\title{
The influence of dietary supplementation with the leucine metabolite $\beta$-hydroxy- $\beta$-methylbutyrate (HMB) on chemotaxis, phagocytosis and respiratory burst of peripheral blood granulocytes and monocytes in calves
}

Roman Wójcik ( $\square$ brandy@uwm.edu.pl )

University of Warmia and Mazury in Olsztyn https://orcid.org/0000-0002-7405-6328

Joanna Małaczewska

Uniwersytet Warminsko-Mazurski Wydzial Medycyny Weterynaryjnej

Grzegorz Zwierzchowski

Uniwersytet Warminsko-Mazurski Wydzial Biologii i Biotechnologii

Jan Miciński

Uniwersytet Warminsko-Mazurski Wydzial Bioinżynierii Żwierząt

Edyta KaczorekŁukowska

Uniwersytet Warminsko-Mazurski Wydzial Medycyny Weterynaryjnej

Research article

Keywords: $\beta$-hydroxy- $\beta$-methylbutyrate, granulocytes, monocytes, chemotaxis, phagocytosis, respiratory burst calves

Posted Date: January 9th, 2020

DOI: https://doi.org/10.21203/rs.2.20386/v1

License: (c) (i) This work is licensed under a Creative Commons Attribution 4.0 International License. Read Full License

Version of Record: A version of this preprint was published at BMC Veterinary Research on June 1st, 2020. See the published version at https://doi.org/10.1186/s12917-020-02389-1. 


\section{Abstract}

Background The objective of this study was to evaluate the effect of HMB on the chemotactic activity, phagocytic activity and respiratory metabolism of peripheral blood granulocytes and monocytes in calves.

Method The experiment was performed on 14 calves aged $30 \pm 2$ days, divided into two equal groups of control (group I) and experimental (group II) animals. The feed administered to experimental group calves was supplemented with HMB (Metabolic Technologies Inc. Ames, IA, USA) at $40 \mathrm{mg} / \mathrm{kg}$ BW, whereas control calves were administered standard farm-made feed without supplementation. Blood was sampled from the jugular vein immediately before the experiment (day 0 ) and on experimental days 15, 30 and 60 to determine: chemotactic activity (MIGRATEST ${ }^{\circledR}$ kit), phagocytic activity (PHAGOTEST $®$ kit) and respiratory metabolism (BURSTTEST ${ }^{\circledR}$ kit) of peripheral blood granulocytes and monocytes by flow cytometry.

Results An analysis of granulocyte and monocyte chemotactic activity and phagocytic activity revealed significantly higher levels of phagocytic activity in calves administered HMB than in the control group, expressed in terms of the percentage of phagocytising cells and mean fluorescence intensity (MFI). HMB also had a positive effect on the oxidative metabolism of both granulocytes and monocytes after stimulation with Escherichia coli bacteria and with PMA (4-phorbol-12- $\beta$-myristate-13-acetate), expressed in terms of the percentage of oxidative metabolism and MFI.

Conclusion HMB stimulates non-specific cell-mediated immunity, which is a very important consideration in newborn calves that are exposed to adverse environmental factors in the first weeks of their life. The supplementation of animal diets with HMB for both preventive and therapeutic purposes can also reduce the use of antibiotics in animal production.

\section{Background}

Considerable research has been done into preparations that simulate immune mechanisms, in particular non-specific cell-mediated and humoral immunity, in the youngest animals $[1,2,3,4,5]$. A healthy immune system plays a particularly important role in newborns, including in calves that are far more susceptible to infections (viral, bacterial and other) than adult individuals $[6,7,8]$.

Non-infectious factors, such as the season of birth, low birth weight, unfavorable environment, absence of colostrum feeding after birth or colostrum feeding at an inappropriate time, as well as infectious factors that cause gastrointestinal and respiratory diseases, are the most frequent causes of disease that contribute to high mortality in newborn calves and cause production losses $[6,7,8,9,10,11,12]$. Diarrhoea caused by non-infectious factors, such as inappropriate diet (poor hygiene, feeding milk from cows with mastitis, low quality of milk replacers), as well as bacterial (Escherichia coli, Salmonella, Clostridium) and viral infections (rotaviruses and coronaviruses) is one of the most dangerous diseases affecting calves, and it can account for more than $50 \%$ of mortality $[9,13]$. Calves are also susceptible to 
bronchial pneumonia (bovine flu), a highly infectious disease with varied aetiology that spreads by direct contact between healthy and diseased animals and is caused by more than 20 pathogens, including several types of viruses, mycoplasma and chlamydophila bacteria $[12,13,14]$. These diseases can increase calves' susceptibility to infections caused by facultative pathogens. In young animals, delicate mucosal membranes in the oral cavity, nose and throat are more sensitive to pathogens, including Fusobacterium necrophorum which causes calf diphtheria, a disease that leads to the necrosis of mucous membranes and the underlying tissues [15]. These diseases are difficult to treat and the prognosis is doubtful, which is why prevention, including immunoprevention, could play a very important role in calf rearing $[16,17,18]$. The search for effective immunostimulants, in particular feed additives, continues, and $\beta$-hydroxy- $\beta$-methylbutyrate (HMB) could be one of such supplements.

Beta-hydroxy- $\beta$-methylbutyrate occurs naturally in humans, animals and plants. This endogenous metabolite of the branched-chain amino acid (BCAA) leucine (LEU) is produced when leucine is oxidised in the cell cytoplasm, mainly in the liver and muscles. Nearly $80 \%$ of endogenous LEU is used in protein synthesis, and the remainder is transformed into a-ketoisocaproate (a-KIC) which can undergo further conversion in two processes. The first process occurs in the mitochondria where a-KIC is oxidised to isovaleryl-CoA by branched-chain ketoacid dehydrogenase (BCKAD). 3-hydroxy-3-methylglutarylcoenzyme $A(\mathrm{HMG}-\mathrm{Co}$ ) is synthesised after several steps. An alternative process takes place in the cytosol where HMB is produced from a-KIC by the KIC dioxygenase enzyme. Under normal conditions, approximately $5 \%$ of leucine is metabolised into $\mathrm{HMB}$, whereas $\mathrm{KIC}$ is mostly converted to isovaleryl-CoA $[19,20]$.

Small quantities of HMB are found in alfalfa, corn (corn silage), milk, cheese, citrus fruit (grapefruit), selected fish species (catfish), red wine and red meat. The quantity of HMB that occurs naturally in the body and is supplied with food is insufficient and, therefore, has to be supplemented from external sources. HMB is a safe compound that does not produce side effects even if administered at excessive doses, and excess HMB is excreted with urine [21].

According to research studies conducted on several animal species $[22,23,24,25,26,27,28,29,30,31]$, $\mathrm{HMB}$ can stimulate immune mechanisms. However, little is known about its exact mechanism of action and effects on different immunity parameters in animals, including calves. Therefore, the aim of this study was to evaluate the effect of dietary supplementation with HMB on the chemotaxis, phagocytosis and respiratory burst of peripheral blood granulocytes and monocytes in calves. The present study complements our previous research into the influence of HMB on selected parameters of non-specific cellmediated [29] and humoral immunity [30] in calves.

\section{Results}

The chemotactic activity of peripheral blood neutrophils in calves was expressed as the chemotactic index (Fig. 3, Fig. 4) whose mean values on experimental days 30 and 60 increased significantly $(p<0.01$ or $p<0.001)$ in the group of calves whose diets were supplemented with HMB (experimental group) 
relative to non-supplemented animals (control group). In the experimental group, the mean value of the chemotactic index also increased significantly $(p<0.001)$ on experimental days 30 and 60 relative to its mean baseline value (day 0 ).

The analysis of the phagocytic activity of peripheral blood neutrophils revealed a significant $(p<0.05$ or $p<0.01$ ) increase in the mean percentage of phagocytising neutrophils (Fig. 5, Fig. 6) in the experimental group relative to the control group throughout the entire experiment, as well as a significant $(p<0.05)$ increase in the mean percentage of phagocytising neutrophils (Fig. 5) in the experimental group on days 30 and 60 relative to the mean baseline value (day 0 ). The MFI of granulocytes, which denotes the number of bacteria ingested per phagocyte (Fig. 7), increased significantly $(p<0.01$ or $p<0.001)$ between experimental days 15 and 30 in the experimental group relative to the control group and relative to the mean baseline value (day 0 ).

The phagocytic activity of peripheral blood monocytes, expressed as the mean percentage of phagocytising neutrophils (Fig. 8, Fig. 9), on experimental days 30 and 60 increased significantly $(p<$ 0.001 or $p<0.0001$ ) in the experimental group relative to the control group and relative to the mean baseline value (day 0 ). Similarly to neutrophils, the MFI of monocytes, which denotes the number of bacteria ingested per phagocyte (Fig. 10), increased significantly $(p<0.01$ or $p<0.001)$ between experimental days 15 and 30 in the experimental group relative to the control group and relative to the mean baseline value (day 0 ).

The respiratory burst activity (metabolism of highly reactive oxygen species) of peripheral blood neutrophils increased in the experimental group fed HMB-supplemented diets relative to the control group and relative to the mean baseline value (day 0 ) throughout the entire experiment. An increase was observed in the mean percentage of cells stimulated to undergo respiratory burst (Fig. 11, Fig. 12) and in the MFI of neutrophils denoting the respiratory burst activity of different neutrophils (Fig. 13). However, a significant $(p<0.05$ or $p<0.01$ or $p<0.001$ or $p<0.0001)$ increase in the mean values of the above parameters was observed only after stimulation with potent respiratory burst activators, PMA and E. coli bacteria, throughout the entire experiment. The stimulation with $\mathrm{N}$-formyl-methionyl-leucyl-phenylalanine (fMLP), a weak activator of respiratory burst, did not induce significant differences in the mean percentage of cells stimulated to undergo respiratory burst or the MFI of neutrophils between the control group and the experimental group or relative to the mean baseline values (day 0) (Fig. 11).

Similarly to granulocytes, the stimulation of peripheral blood monocytes with E. coli, PMA and fMLP significantly $(p<0.05$ or $p<0.01$ or $p<0.001)$ increased the mean percentage of cells stimulated to undergo respiratory burst (Fig. 14, Fig. 15) and the mean intensity of respiratory burst in monocytes (Fig. 16) in the experimental group relative to the control group and relative to mean baseline values (day $0)$.

\section{Discussion}


This study evaluated the effect of the supplementation of calf diets with HMB, a natural metabolite of leucine, on different stages of phagocytosis: chemotaxis and intracellular ingestion and killing of bacteria by peripheral blood granulocytes and monocytes.

As the key components of non-specific cell-mediated immunity, neutrophils and monocytes constitute the first line of defence against pathogens in the body. Their main mechanism of action is phagocytosis during which antigens are recognised and bound by different receptors on the surface of phagocytes, they are engulfed, ingested and killed in cells, and then eliminated from the body [33]. This process plays a particularly important role in young animals that are more susceptive to negative stimuli and external factors, including bacteria, than adult individuals. Calves face numerous challenges in early life, which may compromises their growth, feed intake, metabolism and health. In most cases, these adverse events are highly correlated with immune deficiencies (physiological) resulting from incompletely developed or impaired immune mechanisms $[13,34,35]$.

There is considerable evidence to indicate that HMB stimulates non-specific immune mechanisms, including phagocytosis, in many animal species $[23,25,27,36,37,38,39]$ however, these effects have been rarely investigated in calves [29]. HMB is a strong anticatabolic agent and a regulator of protein metabolism, and it is widely used in sports and bodybuilding to increase strength, muscle mass and exercise performance $[40,41,42,43,44]$. Immune health is also highly correlated with protein synthesis because mounting immune responses require the generation of new cells and the synthesis of antigenpresenting machinery, immunoglobulins, cytokines, cytokine receptors and acute phase proteins.

In the present study, the observed increase in the chemotactic activity of peripheral blood neutrophils, expressed as the chemotactic index as the most accurate parameter for assessing chemotactic activity [45], in the group of experimental calves supplemented with HMB relative to control group calves cannot be compared with published data because such experiments have not been conducted in calves or in other animal species. As mentioned previously, numerous authors $[23,25,27,29,36,37,38,39]$ have reported on the positive effects of HMB on phagocytosis in several animal species, but the supplement's impact on specific stages of phagocytosis has never been described.

The significant increase in the phagocytic activity of monocytes and granulocytes in the experimental group relative to the control group was reflected by an increase in the percentage of phagocytising cells as well as an increase in the mean number of bacteria ingested per phagocyte, expressed as MFI. Similar results were noted in our previous studies of geese [25] and goats [46]. In a study by Siwicki et al. [38], the potential killing activity (PKA) of granulocytes and monocytes increased by $140 \%$ in fish (rainbow trout and carp) stimulated with various doses of $\mathrm{HMB}$ relative to the control group. The analysed supplement exerted the most stimulatory effect on PKA when administered at doses higher than $50 \mathrm{mg} \mathrm{HMB} / \mathrm{mL}$. A study of rainbow trout [39] fed pellets with various $\operatorname{HMB}$ content $(0,10,25$ or $50 \mathrm{mg} / \mathrm{kg} \mathrm{BW} /$ day) for 8 weeks confirmed that HMB stimulates the activity of phagocytes ( $100 \%$ increase in PKA) relative to the control group. Similar results were reported by Siwicki et al. [47] who examined the effect of two HMB doses (50 and $100 \mathrm{mg} \mathrm{HMB} / \mathrm{kg} \mathrm{BW/day)} \mathrm{administered} \mathrm{over} \mathrm{a} \mathrm{period} \mathrm{of} 4$ weeks on non-specific cell- 
mediated immunity in the common carp (Cyprinus carpio). The PKA of pronephric phagocytes was significantly higher $(p<0.05)$ in HMB-fed carp than in the control group. However, significant differences were not observed between experimental carp administered HMB doses of 50 and $100 \mathrm{mg} / \mathrm{kg} \mathrm{BW} /$ day.

In the current study, HMB also significantly enhanced the intracellular killing activity of granulocytes and monocytes stimulated with strong mitogens (PMA and E. coli bacteria), which was expressed by an increase in the percentage of cells stimulated to undergo respiratory burst and in MFI in these cells. Higher values of the above parameters indicate that pathogens were more effectively eliminated from the body by phagocytising cells. Similar results were reported by Siwicki et al. [39], where a spectrophotometric analysis in the respiratory burst activity test revealed that the production of highly reactive oxygen species by head kidney phagocytes doubled in rainbow trout whose diets were supplemented with HMB for 8 weeks. In a study of rainbow trout (Oncorhynchus mykiss) and carp (Cyprinus carpio) [38], the addition of $>50 \mathrm{mg} / \mathrm{ml} \mathrm{HMB}$ to the culture medium increased respiratory burst activity by up to $84 \%(p<0.01)$ in pronephric phagocytes grown in a culture medium (RPMI-1640) containing $0,0.1,1,5,10,25,50$ or $100 \mathrm{mg} \mathrm{HMB} / \mathrm{mL}$ relative to the cells cultured without HMB. In an in vitro study, Peterson et al. [37] evaluated macrophages that were isolated from a chicken macrophage cell line (MQ-NCSU) and cultured in the presence of 20, 40 and $80 \mu \mathrm{g}$ of HMB. Supernatant fractions were also tested for the presence of nitrite. The phagocytic potential of MQ-NCSU macrophages exposed to $40 \mu \mathrm{g}$ of HMB was significantly higher (31.7\%) relative to the controls. Sephadex-elicited macrophages treated with $80 \mu \mathrm{g} \mathrm{HMB}$ exhibited a 14.4\% increase in phagocytosis compared with controls.

The mechanism by which HMB influences phagocytising cells and other immunocompetent cells, isolated in this experiment, has not yet been fully elucidated. It can be hypothesised that as a leucine catabolite, HMB is an abundant source of energy for biological activities [19] or that it is an effector of energy metabolism. HMB can also influence opsonisation or the binding of opsonin-pathogen complexes by specialised membrane receptors on the surface of phagocytes. The above hypothesis was validated by Gonzales et al. [48] who reported an increase in the expression of complement receptor 3 (CR3) on CD14 + monocytes in men orally administered $\beta$-hydroxy- $\beta$-methylbutyrate free acid (HMB-FA). CD14 + monocytes play an auxiliary role in phagocytosis, but are unable to initiate this process. Phagocytosis is initiated when the molecules involved in adhesion and activation of phagocytosis, such as complement components (iC3b), are bound to receptors. Józefowski et al. [49] demonstrated that CR3 ( $\beta 2$ integrin CD11b/CD18) closely interacts with class A scavenger receptors (SR-A) which recognise and bind pathogens and can also stimulate phagocytosis. According to Peiser et al. [50], Mukhopadhyay et al. [51] and Mukhopadhyay et al. [52], scavenger receptor-mediated phagocytosis is not required for the production of pro-inflammatory cytokines. In a study by Townsend et al. [53], a flow cytometry analysis revealed that the circulating levels of TNF-a (tumour necrosis factor) and TNF-a receptor 1 (TNFR1) in CD14 + monocytes decreased in men whose diets were supplemented with HMB. In an in vitro study of the TE-1 cancer cell line, Miyake et al. [54] demonstrated that HMB inhibited the activation of NF-KB and IL-6 production. In a study by Hoffman et al. [55], the inflammatory response (TNF-a, interleukin (IL)-8, IL10 , granulocyte colony-stimulating factor (GC-SF), interferon (IFN)- $\gamma$, and fractalkine) to intense military training was attenuated and muscle quality was maintained in combat soldiers whose diets were 
supplemented with $\mathrm{HMB}$ for 23 days. These findings clearly indicate that the increase in phagocytic activity, at different stages of the process, noted in the present study in the group of HMB-supplemented calves, could not be directly linked with enhanced production of pro-inflammatory cytokines by HMB.

The results of this study suggest that HMB is a highly effective dietary supplement that stimulates immunity, does not exert toxic effects and can be safely administered to animals. HMB stimulates nonspecific cell-mediated immunity, which is a very important consideration in newborn calves that are exposed to adverse environmental factors in the first weeks of their life. The supplementation of animal diets with HMB for both preventive and therapeutic purposes can also reduce the use of antibiotics in animal production.

\section{Conclusions}

This study demonstrated significantly higher levels of granulocyte chemotactic activity (expressed by the chemotactic index) and phagocytic activity (expressed by the percentage of phagocytes), a significantly higher average number of bacteria eliminated by one phagocyte (expressed by the average fluorescence intensity of monocytes and granulocytes), and significantly higher intracellular killing activity of granulocytes and monocytes stimulated with PMA and E. coli (expressed by the percentage of stimulated cells and average fluorescence intensity) in experimental calves administered HMB than in control group animals whose diets were not supplemented.

\section{Methods}

\section{Experimental design}

The experiment was performed on 14 Polish Holstein-Friesian calves originating from a private dairy herd located in the north-eastern region of Poland. The calves (aged $30 \pm 2$ days) were fed colostrum within 1 hour after birth. Colostrum was administered in the amount of $2 \mathrm{~kg} / \mathrm{animal} /$ day for 5 days. After that period, the animals were fed milk replacers until the age of 8 weeks. Immediately after birth, the calves were moved to wooden sheds outside the cow barn. At the age of one month, calves were included in a 60-day study. Prior to the experiment, the animals were weighed and divided into two groups by the analogue method. The control group (I) comprised calves fed a standard farm-made diet. Between the age of 5 days to 8 weeks, they were fed the Mlekowit (Polmass, Bydgoszcz, Poland) milk replacer in the amount of $4 \mathrm{~L} /$ day/animal in two portions. In the experimental group (II), the same quantity of the milk replacer was supplemented with $\beta$-hydroxy- $\beta$-methylbutyrate (HMB, Metabolic Technologies Inc. Ames, IA, USA) at $40 \mathrm{mg} / \mathrm{kg}$ BW. Beginning from the first week, the animals had unlimited access to solid feed (maize silage, meadow hay and Jösera Kälberkost prestarer) which was supplied in increasing quantities. Fresh water was supplied ad libitum. All calves enrolled in to the study survived the experimental period and were still breed in the herd.

Sample collection 
Blood was sampled from the jugular vein prior to HMB supplementation of feed and on days 15, 30 and 60 of the experiment to determine and compare: chemotactic activity (MIGRATEST ${ }^{\circledR}$ kit) (Glycotope Biotechnology $\mathrm{GmbH}$, Heidelberg, Germany), phagocytic activity (PHAGOTEST® kit) (Orpegen Pharma, Heidelberg, Germany) and respiratory metabolism (BURSTTEST ${ }^{\circledR}$ kit) (Orpegen Pharma, Heidelberg, Germany) of peripheral blood granulocytes and monocytes by flow cytometry.

Determination of the Chemotactic Activity of Blood Granulocytes and Monocytes in Calves with the MIGRATEST ${ }^{\circledR}$ kit

The assay was performed according to the manufacturer's specifications (Orpegen Pharma, Heidelberg, Germany). Briefly, test main principle bases on the assessment of the number of migrated neutrophils towards a concentration gradient of the chemoattractant fMLP, as well as measurement of Lselectin shedding of activated cells. The chemotactic index was calculated by dividing the number of cells that migrated towards fMLP by the number of cells that migrated in the absence of fMLP [32]. More details regarding analytical protocol were given previously [46].

Determination of the Phagocytic Activity of Blood Granulocytes and Monocytes in Calves with the PHAGOTEST ${ }^{\circledR}$ kit

Phagocytic Activity of Blood Granulocytes and Monocytes was determined with PHAGOTEST® kit (Orpegen Pharma, Heidelberg, Germany) according to the manufacturer's specifications. The detailed method how the test was performed have been described previously [46]. Briefly, the Phagotest involves E. coli bacteria stained with fluorescein (FITC). The main principle of Phagotest is to assess the number of phagocytosing cells, granulocytes and monocytes separately, as well as their respective phagocytic activity. Specifically, to count the number of bacterial cells absorbed by a single immune based on fluorescence intensity change. Determination of the Oxidative Metabolism of Blood Granulocytes and Monocytes in Calves with the BURSTTEST ${ }^{\circledR}$ Kit

BURSTTEST assay was performed in accordance with the manufacturer's recommendations in the leaflet attached to the product (Orpegen Pharma, Heidelberg, Germany). Briefly, kit targets quantitative determination of leukocyte oxidative burst in heparinized whole blood. It employs opsonized bacteria (E.coli), phorbol 12-myristate 13-acetate (PMA) and the chemotactic peptide N-formyl-Met-Leu-Phe (fMLP) as stimulants, and fluorogenic substrate [Dihydrorhodamine (DHR-123)].

The test allows determination of the percentage of phagocytic cells based on DHR-123 convertion to the fluorescence emitter (rhodamine 123 (R123) cation) due to the oxidation in mitochondria in the presence of $\mathrm{H} 2 \mathrm{O} 2$. The protocol has been described in detailes previously [46].

FACS Acquisition and Analysis

Flow cytometry was performed with the FACSCanto II cytometer (BD Biosciences, San Jose, California, USA). Data were acquired with FACSDiva version 6.1.3 software (BD Biosciences, San Jose, California, USA) and analysed in FlowJo 10 software (Tree Star, Ashland, Oregon, USA). The cytometry 
setup and tracking beads (CST; BD Biosciences, San Jose, California, USA) were used to initialise the photomultiplier tube (PMT). Unstained control cells and a single stain control for every fluorochrome were prepared and used to establish flow cytometric compensation (Figure 1).

Granulocytes and counting beads were identified in PerCP to SSC scatter and depicted in FSC to SSC scatter. Data acquisition ended after the acquisition of exactly 2000 events in the region of counting beads. The number of events in the region of granulocytes was counted, and the number of granulocytes in the control sample was compared with the number of granulocytes in the positive control sample after stimulation with $\mathrm{FMLP}$. The decrease in L-selectin expression can be measured simultaneously. Downregulation of this cell adhesion molecule correlates directly with the activation of neutrophils under exposure to chemotactic factors. Changes in cell shape precede cell migration and can be measured by analysing changes in forward scatter signals during flow cytometry (Figure 2).

Statistical Analysis

Numerical results were presented as the arithmetic mean \pm SD. The obtained results were processed statistically by two-way ANOVA for orthogonal design. In post-hoc analysis, Dunnett's test was used to compare day 0 with days 15, 30, and 60 in group II (significance of differences between days: (A) $p<0.05$; (B) $p<0.01$; (C) $p<0.001$; (D) $p<0.0001$ ), and Tukey's test for equal groups to compare group II with group I at each time point (significance of differences between groups: ${ }^{\star} p<0.05$; ${ }^{\star \star} p<0.01$; $* \star \star p<$ $0.001 ; * \star \star \star ~ p<0.0001$ ) with the use of GraphPad Prism 7 software. The significance level has been set to $5 \% \mathrm{HMB}$.

\section{Abbreviations}

BCAA - branched-chain amino acid

BW - body weight

CD - cluster of differentiation

CR3 - complement receptor 3

fMLP - N-formyl-methionyl-leucyl-phenylalanine

GC-SF - granulocyte colony-stimulating factor

HMB - $\beta$-hydroxy- $\beta$-methylbutyrate

HMB-FA - $\beta$-hydroxy- $\beta$-methylbutyrate free acid

HMG-CoA - 3-hydroxy-3-methylglutaryl-coenzyme A 
IFN- $\boldsymbol{\gamma}$ - interferon- $\boldsymbol{\gamma}$

IL - interleukin

LEU - leucine

MFI - mean fluorescence intensity

PKA - potential killing activity

PMA - 4-phorbol-12- $\beta$-myristate-13-acetate

SR-A - class A scavenger receptors

TNFR1 - TNF-a receptor 1

TNF-a - tumour necrosis factor a

a-KIC - a-ketoisocaproate

\section{Declarations}

\section{Ethics approval and consent to participate}

Animal experiments were carried out in conformance with the Animal Protection Law (Journal of Laws of 24 February 2005, No. 33, item 289) and upon the recommendations of the Animal Ethics Committee of the University of Warmia and Mazury in Olsztyn. This study was conducted upon the approval of the local Ethics Committee (decision no. 18/2013/N). The herd owner gave written informed consent to use the animals in the study.

\section{Consent for publication}

Not applicable

\section{Availability of data and materials}

The datasets used and/or analysed during the current study are available from the corresponding author on reasonable request.

\section{Competing interests}

The authors declare that they have no competing interests.

\section{Funding}


"Project financially co-supported by Minister of Science and Higher Education in the range of the program entitled "Regional Initiative of Excellence" for the years 2019-2022, Project No. 010/RID/2018/19, amount of funding 12.000.000 PLN."

\section{Authors' contributions}

RW: conceptualization, methodology, software, validation, formal analysis, investigation, resources, data curation, writing-original draft preparation, writing-review and editing, visualization, supervision, project administration, funding acquisition;

JMa: conceptualization, methodology, software, validation, formal analysis, investigation, data curation, writing-original draft preparation, writing-review and editing;

GZ: conceptualization, validation, investigation, resources, writing-review and editing, supervision;

JMi: conceptualization, validation, investigation, writing-review and editing, funding acquisition;

EK-t: investigation, writing-review and editing, visualization;

All authors have read and approved the manuscript.

\section{Acknowledgements}

Not applicable

\section{References}

1.

Wójcik R, Milewski S, Małaczewska J, Tański Z, Brzostowski H, Siwicki AK. Defence mechanisms of the offspring of ewes fed a diet supplemented with yeast (Saccharomyces cerevisiae) during pregnancy and lactation. Centr Eur J Immunol. 2008;33:197-201.

2.

Milewski S, Sobiech P, Bednarek D, Wójcik R, Małaczewska J, Zaleska B, Siwicki AK. Effect of oligosaccharides supplementation on the meat performance traits and selected indicators of humoral immunity in lambs. Bull Vet Inst Pulawy. 2010;54:175-9.

3.

Wójcik R. Effect of brewer's yeast (Saccharomyces cerevisiae) extract on selected parameters of humoral and cellular immunity in lambs. Bull Vet Inst Pulawy. 2010;54:181-7.

4.

Ząbek K, Milewski S, Wójcik R, Siwicki AK. Effect of $\beta-1,3 / 1,6-D-g l u c a n$ in diet on productivity and humoral and cellular defense mechanisms in sheep. Acta Vet Brno. 2013;82:141-6.

5.

Page 11/32 
Wójcik R. The effect of Leiber Beta-S on the selected parameters of immunity in calves. Acta Vet Brno. 2014;83:113-8.

6.

Godden S. Colostrum management for dairy calves. Vet Clin North Am Food Anim Pract. 2008;24:19-39. 7.

Lora I, Gottardo F, Contiero B, Dall Ava B, Bonfanti L, Stefani A, Barberio A. Association between passive immunity and health status of dairy calves under 30 days of age. Prev Vet Med. 2018;152:12-5.

8.

Cooke RF. Effects on animal health and immune function. Vet Clin North Am Food Anim Pract. 2019;35:331-41.

9.

McGuirk SM. Disease management of dairy calves and heifers. Vet Clin North Am Food Anim Pract. 2008;24:139-53.

10.

Mee JF. Newborn dairy calf management. Vet Clin North Am Food Anim Pract. 2008;24:1-17. 11.

Uetake K. Newborn calf welfare: a review focusing on mortality rates. Anim Sci J. 2013;84:101-5. 12.

Reiten M, Rousing T, Thomsen PT, Otten ND, Forkman B, Houe H, Sørensen JT, Kirchner MK. Mortality, diarrhea and respiratory disease in Danish dairy heifer calves: Effect of production system and season. Prev Vet Med. 2018;155:21-6.

13.

Windeyer MC, Leslie KE, Godden SM, Hodgins DC, Lissemore KD, LeBlanc SJ. Factors associated with morbidity, mortality, and growth of dairy heifer calves up to 3 months of age. Prev Vet Med. 2014;113:231-40.

14.

Svensson C, Hultgren J, Oltenacu PA. Morbidity in 3-7-mont-old dairy calves in south-western Sweden, and risk factors for diarrhea and respiratory disease. Prev Vet Med. 2006;74:162-79.

15.

Roberts GL. Fusobacterial infections: an underestimated threat. Br J Biomed Sci. 2000;57:156-62. 16.

Garcia M, Shin JH, Schlaefli A, Greco LF, Maunsell FP, Thatcher WW, Santos JE, Staples CR. Increasing intake of essential fatty acids from milk replacer benefits performance, immune responses, and health of preweaned Holstein calves. J Dairy Sci. 2015;98:458-77.

17.

Hernández-Castellano LE, Özçelik R, Hernandez LL, Bruckmaier RM. Short communication:

Supplementation of colostrum and milk with 5-hydroxy-l-tryptophan affects immune factors but not growth performance in newborn calves. J Dairy Sci. 2018;101:794-800.

18. 
Flaga J, Korytkowski Ł, Górka P, Kowalski ZM. The effect of docosahexaenoic acid-rich algae supplementation in milk replacer on performance and selected immune system functions in calves. $\mathrm{J}$ Dairy Sci. 2019;102:8862-73.

19.

Nissen SL, Abumrad NN. Nutritional role of the leucine metabolite $\beta$-hydroxy- $\beta$-methylbutyrate (HMB). J Nutr Biochem. 1997;8:1-12.

20.

Van Koevering M, Nissen S. Oxidation of leucine and alpha-ketoisocaproate to beta-hydroxy-beta methylbutyrate in vivo. Am J Physiol. 1992;262:E27-31.

21.

Vukovich MD, Slater G, Macchi MB, Turner MJ, Fallon K, Boston T, Rathmacher J. Beta-hydroxy-betamethylbutyrate (HMB) kinetics and the influence of glucose ingestion in humans. J Nutr Biochem. 2001;12:631-9.

22.

Gatnau R, Zimmerman DR, Nissen SL, Wannemuehler M, Ewan RC. Effects of excess dietary leucine and leucine catabolites on growth and immune responses in weanling pigs. J Anim Sci. 1995;73:159-65. 23.

Peterson AL, Qureshi MA, Ferket PR, Fuller JC Jr. Enhancement of cellular and humoral immunity in young broilers by the dietary supplementation of beta-hydroxy-beta-methylbutyrate. Immunopharmacol Immunotoxicol. 1999;21:307-30.

24.

Krakowski L, Krzyżanowski J, Wrona Z, Kostro K, Siwicki AK. The influence of nonspecific immunostimulation of pregnant sows on the immunological value of colostrums. Vet Immunol Immunopath. 2002;87:89-95.

25.

Puchajda-Skowrońska H, Siwicki AK, Wójcik R, Pudyszak K. Effects of 3-hydroxy-3-methylbutyrate (HMB) on selected performance indices and non-specific defence mechanisms in geese. Med Weter. 2006;62:89-92.

26.

Siwicki AK, Fuller JC Jr, Nissen S, Morand M, Pozet F, Vincent F, Kazuń B. Effect of HMB ( $\beta$-hydroxy- $\beta$ methylbutyrate) on in vitro proliferative responses of sheatfish (Silurus glanis) and catfish (Ictalurus melas) lymphocytes stimulated by mitogens. Acta Vet Brno. 2004;73:119-22.

27.

Siwicki AK, Zakęś Z, Fuller JC Jr, Nissen S, Kazuń K, Głąbski E. The influence of $\beta$-hydroxy- $\beta$ methylbutyrate (HMB) on cell-mediated immunity in tench Tinca tinca (L.): in vitro and in vivo study. Aquacult Int. 2006;14:153-61.

28.

Flummer C, Theil PK. Effect of $\beta$-hydroxy $\beta$-methyl butyrate supplementation of sows in late gestation and lactation on sow production of colostrum and milk and piglet performance. J Anim Sci. 2012;90:372-4. 
29.

Wójcik R, Małaczewska J, Siwicki AK, Miciński J, Zwierzchowski G. The effect of $\beta$-hydroxy- $\beta$ methylbutyrate (HMB) on the proliferative response of blood lymphocytes and the phagocytic activity of blood monocytes and granulocytes in calves. Pol J Vet Sci. 2013;16:567-9.

30 .

Wójcik R, Małaczewska J, Siwicki AK, Miciński J, Zwierzchowski G. The effect of $\beta$-hydroxy- $\beta$ methylbutyrate (HMB) on selected parameters of humoral immunity in calves. Pol J Vet Sci. 2014;17:357-9.

31.

Ząbek K, Wójcik R, Milewski S, Małaczewska J, Tański Z, Siwicki AK. Effect of $\beta$-hydroxy- $\beta$-methylbutyrate acid on meat performance traits and selected indicators of humoral immunity in goats. Jpn J Vet Res. 2016;64:247-56.

32.

Guilhem A, Malcus C, Clarivet B, Plauchu H, Dupuis-Girod S. Immunological abnormalities associated with hereditary haemorrhagic telangiectasia. J Intern Med. 2013;274:351-62.

33.

Abbas AK, Lichtman AH, Pillai S. Innate immunity. In: Abbas AK, Lichtman AH, Pillai S, editors. Basic Immunology. Functions and Disorders of the Immune System. Philadelphia: Elsevier Inc; 2014. pp. 2552.

34.

Donovan GA, Dohoo IR, Montgomery DM, Bennett FL. Associations between passive immunity and morbidity and mortality in dairy heifers in Florida, USA. Prev Vet Med. 1998;34:31-46.

35.

Stefaniak T, Jawor P. The most important causes of failure of passive transfer in calves kept in dairy farms. Folia Univ Agric Stetin Zootechnica. 2006;250:45-50.

36.

Ostaszewski P, Kozlowska E, Siwicki AK, Krzyzanowski J, Fuller JC Jr, Nissen S. The immunomodulating activity of dietary ß-hydroxy-ß-methylbutyrate (HMB) in weanling pigs. J Anim Sci. 1998;76(Suppl.1):136. 37.

Peterson A, Qureshi M, Ferket P, Fuller J Jr. In vitro exposure with $\beta$-hydroxy- $\beta$-methylbutyrate enhances chicken macrophage growth and function. Vet Immunol Immunopathol. 1999;67:67-78.

38.

Siwicki AK, Fuller JC Jr, Nissen S, Ostaszewski P, Studnicka M. In vitro effects of beta-hydroxy-betamethylbutyrate (HMB) on cell-mediated immunity in fish. Vet Immunol Immunopathol. 2000;76:191-7. 39.

Siwicki AK, Morand M, Fuller JC Jr, Nissen S, Goryczko K, Ostaszewski P, Kazuń K, Głombski E. Influence of feeding the leucine metabolite $\beta$-hydroxy- $\beta$-methylbutyrate (HMB) on the non-specific cellular and humoral defence mechanisms of rainbow trout (Oncorhynchus mykiss). J Appl Ichthyol. 2003;19:44-8. 40. 
Ostaszewski P, Kostiuk S, Balasinska B, Jank M, Papet I, Glomot F. The leucine metabolite 3-hydroxy-3methylbutyrate (HMB) modifies protein turnover in muscles of laboratory rats and domestic chickens in vitro. J Anim Physiol Anim Nutr. 2000;84:1-8.

41.

Slater G, Jenkins D, Logan P, Lee H, Vukovich M, Rathmacher JA, Hahn AG. Beta-hydroxy-beta-

methylbutyrate (HMB) supplementation does not affect changes in strength or body composition during resistance training in trained men. Int J Sport Nutr Exerc Metab. 2001;11:384-96.

42.

Ransone J, Neighbors K, Lefavi R, Chromiak J. The effect of beta-hydroxy beta-methylbutyrate on muscular strength and body composition in collegiate football players. J Strength Cond Res. 2003;17:34-9.

43.

Thomson JS, Watson PE, Rowlands DS. Effects of nine weeks of beta-hydroxy-beta-methylbutyrate supplementation on strength and body composition in resistance trained men. J Strength Cond Res. 2009;23:827-35.

44.

Wilkinson DJ, Hossain T, Hill DS, Phillips BE, Crossland H, Williams J, Loughna P, Churchward-Venne TA, Breen L, Phillips SM, Etheridge T, Rathmacher JA, Smith K, Szewczyk NJ, Atherton PJ. Effects of leucine and its metabolite beta-hydroxy-beta-methylbutyrate on human skeletal muscle protein metabolism. J Physiol. 2013;591:2911-23.

45.

Wójcik R, Małaczewska J, Kaczorek-Łukowska E. The applicability of the Migratest® kit for evaluating the chemotactic activity of peripheral blood neutrophils in goats on the example of animals supplemented with $\beta$-hydroxy- $\beta$-methylbutyrate (HMB). Pol J Vet Sci 2019;22: doi.org/10.5601/jelem.2019.24.4.1529. 46.

Wójcik R, Ząbek K, Małaczewska J, Milewski S, Kaczorek-Łukowska E. The effects of $\beta$-hydroxy- $\beta$ methylbutyrate (HMB) on chemotaxis, phagocytosis, and oxidative burst of peripheral blood granulocytes and monocytes in goats. Animals. 2019;9:1031.

47.

Siwicki AK, Głąbski E, Kazuń K, Kazuń B, Lepa A, Majewicz-Zbikowska M. Effect of dietary administration of the $\beta$-hydroxy- $\beta$-methylbutyrate on the innate immunity and protection against motile Aeromonas septicaemia in fish. Centr Eur J Immunol. 2011;36:135-38.

48.

Gonzalez AM, Fragala MS, Jajtner AR, Townsend JR, Wells AJ, Beyer KS, Boone CH, Pruna GJ, Mangine GT, Bohner JD, Fukuda DH, Stout JR, Hoffman JR. Effects of $\beta$-hydroxy- $\beta$-methylbutyrate free acid and cold water immersion on expression of CR3 and MIP-1 $\beta$ following resistance exercise. Am J Physiol Regul Integr Comp Physiol. 2014;306:R483-9.

49.

Józefowski S, Yang Z, Marcinkiewicz J, Kobzik L. Scavenger receptors and $\beta$-glucan receptors participate in the recognition of yeasts by murine macrophages. Inflamm Res. 2012;61:113-26. 
50.

Peiser L, De Winther MP, Makepeace K, Hollinshead M, Coull P, Plested J, Kodama T, Moxon ER, Gordon S. The class A macrophage scavenger receptor is a major pattern recognition receptor for Neisseria meningitidis which is independent of lipopolysaccharide and not required for secretory responses. Infect Immun. 2002;70:5346-54.

51.

Mukhopadhyay S, Peiser L, Gordon S. Activation of murine macrophages by Neisseria meningitidis and IFN-gamma in vitro: distinct roles of class A scavenger and Toll-like pattern recognition receptors in selective modulation of surface phenotype. J Leukoc Biol. 2004;76:577-84.

52.

Mukhopadhyay S, Chen Y, Sankala M, Peiser L, Pikkarainen T, Kraal G, Tryggvason K, Gordon S. MARCO, an innate activation marker of macrophages, is a class A scavenger receptor for Neisseria meningitidis. Eur J Immunol. 2006;36:940-9.

53.

Townsend JR, Fragala MS, Jajtner AR, Gonzalez AM, Wells AJ, Mangine GT, Robinson EH 4th, McCormack WP, Beyer KS, Pruna GJ, Boone CH, Scanlon TM, Bohner JD, Stout JR, Hoffman JR. $\beta$ Hydroxy- $\beta$-methylbutyrate (HMB)-free acid attenuates circulating TNF- $\alpha$ and TNFR1 expression post resistance exercise. J Appl Physiol. 2013;115:1173-82.

54.

Miyake S, Ogo A, Kubota H, Teramoto F, Hirai T. $\beta$-Hydroxy- $\beta$-methylbutyrate suppresses NF-kB activation and IL-6 production in TE-1 cancer cells. In Vivo. 2019;33:353-8.

55 .

Hoffman JR, Gepner Y, Stout JR, Hoffman MW, Ben-Dov D, Funk S, Daimont I, Jajtner AR, Townsend JR, Church DD. $\beta$-Hydroxy- $\beta$-methylbutyrate attenuates cytokine response during sustained military training. Nutr Res. 2016;36:553-63.

\section{Figures}




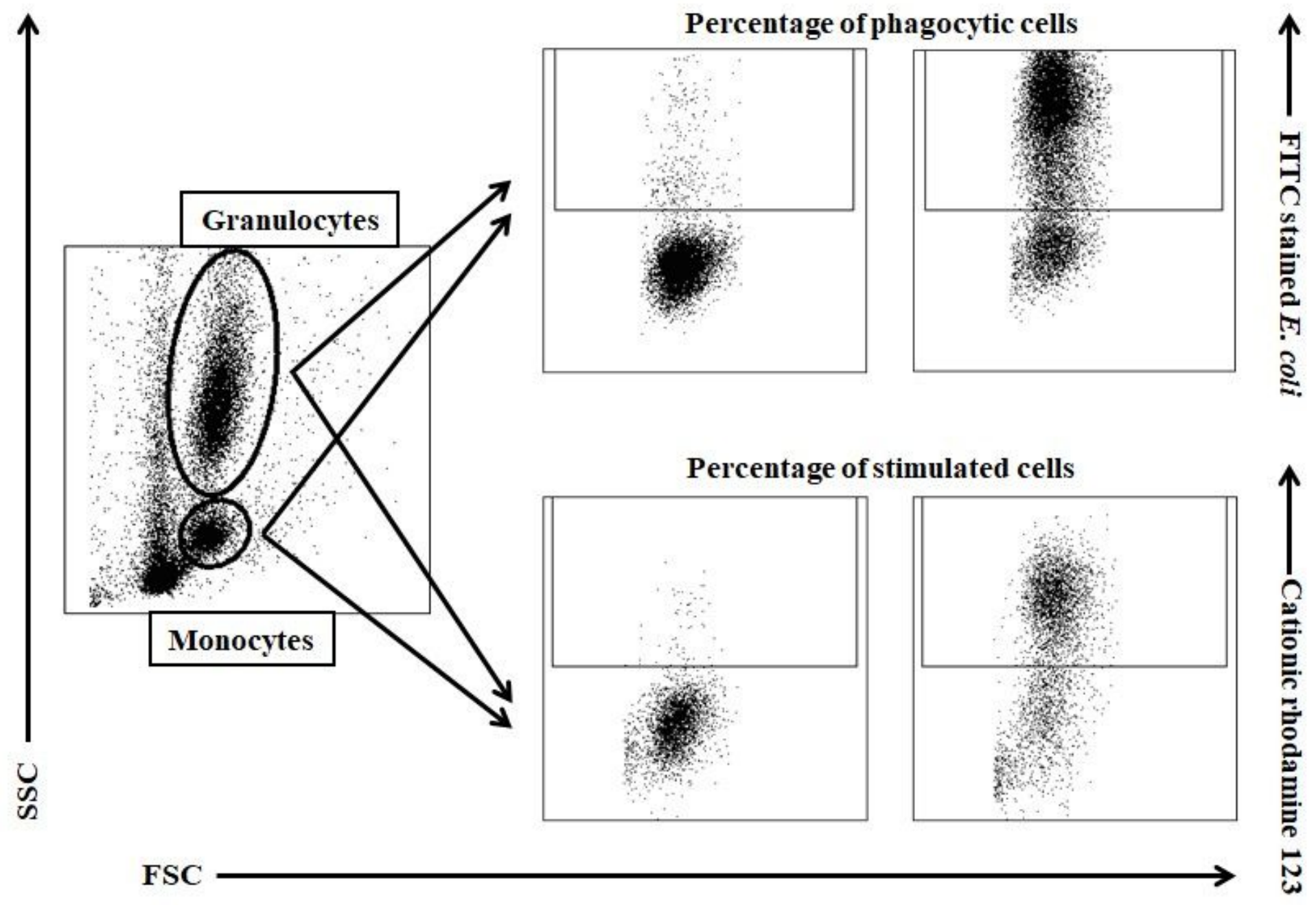

Figure 1

Gating strategy for flow cytometry data analysis. Granulocytes and monocytes were gated based on forward and side scatter (FSC/SSC) parameters. Each cell subset was analysed for the relative number of phagocytising cells and cells stimulated for respiratory burst (fMLP, PMA or E. coli bacteria). 


\section{Negative control}

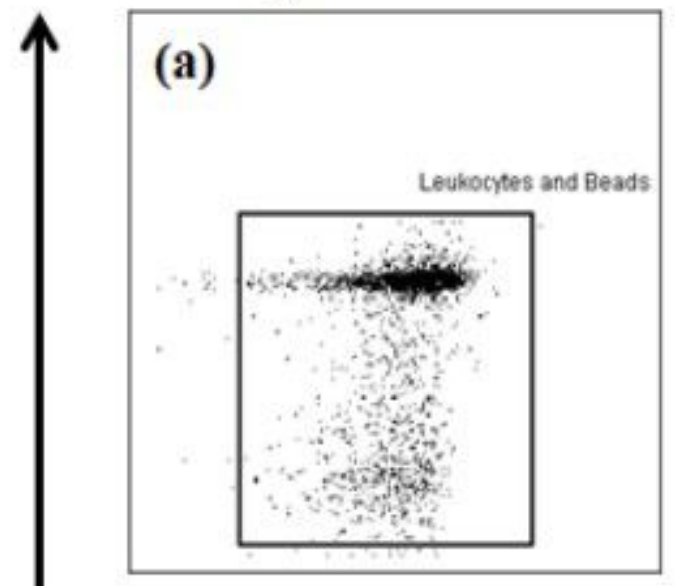

(c)

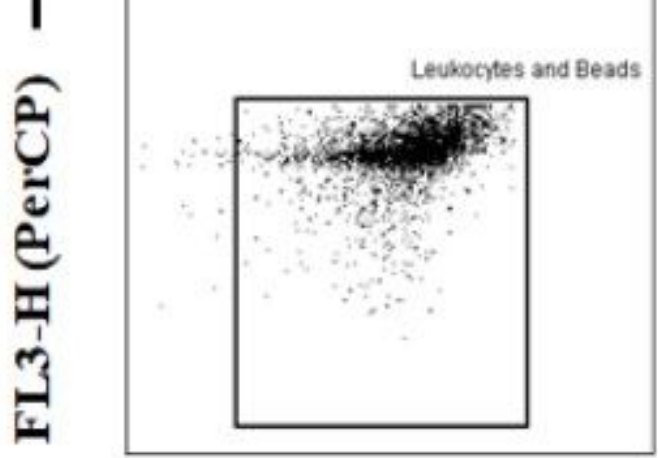

\section{Stimulation with fMLP}
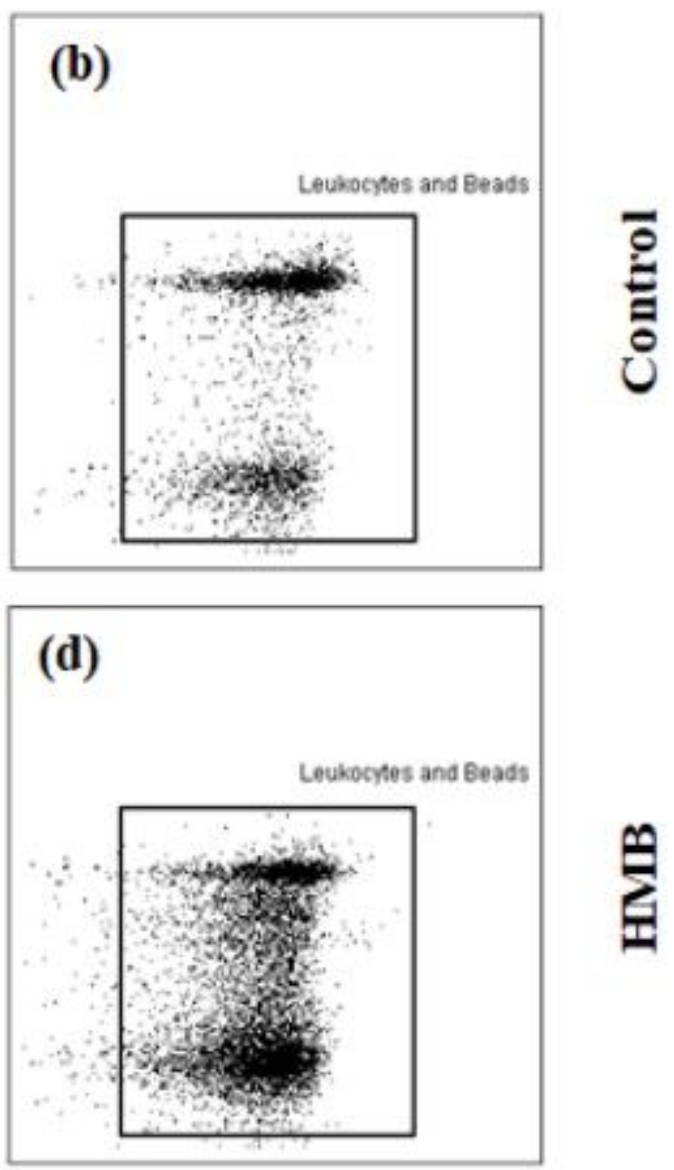

\section{SSC-H}

\section{Figure 2}

Gating strategy for analysing flow cytometry data based on the neutrophil migration assay. Granulocytes and counting beads were identified in PerCP to SSC scatter and depicted in FSC to SSC scatter. (a) control without stimulation; (b) - control stimulated with fMLP; (c) - HMB without stimulation; (d) HMB stimulated with $\mathrm{fMLP}$; 
$\rightarrow$ chemotactic index of neutrophils $( \pm S D)$ - control group $(I)-$ chemotactic index of neutrophils $( \pm S D)$ - experimental group - HMB (II)

6

5

4

3

2

1

0

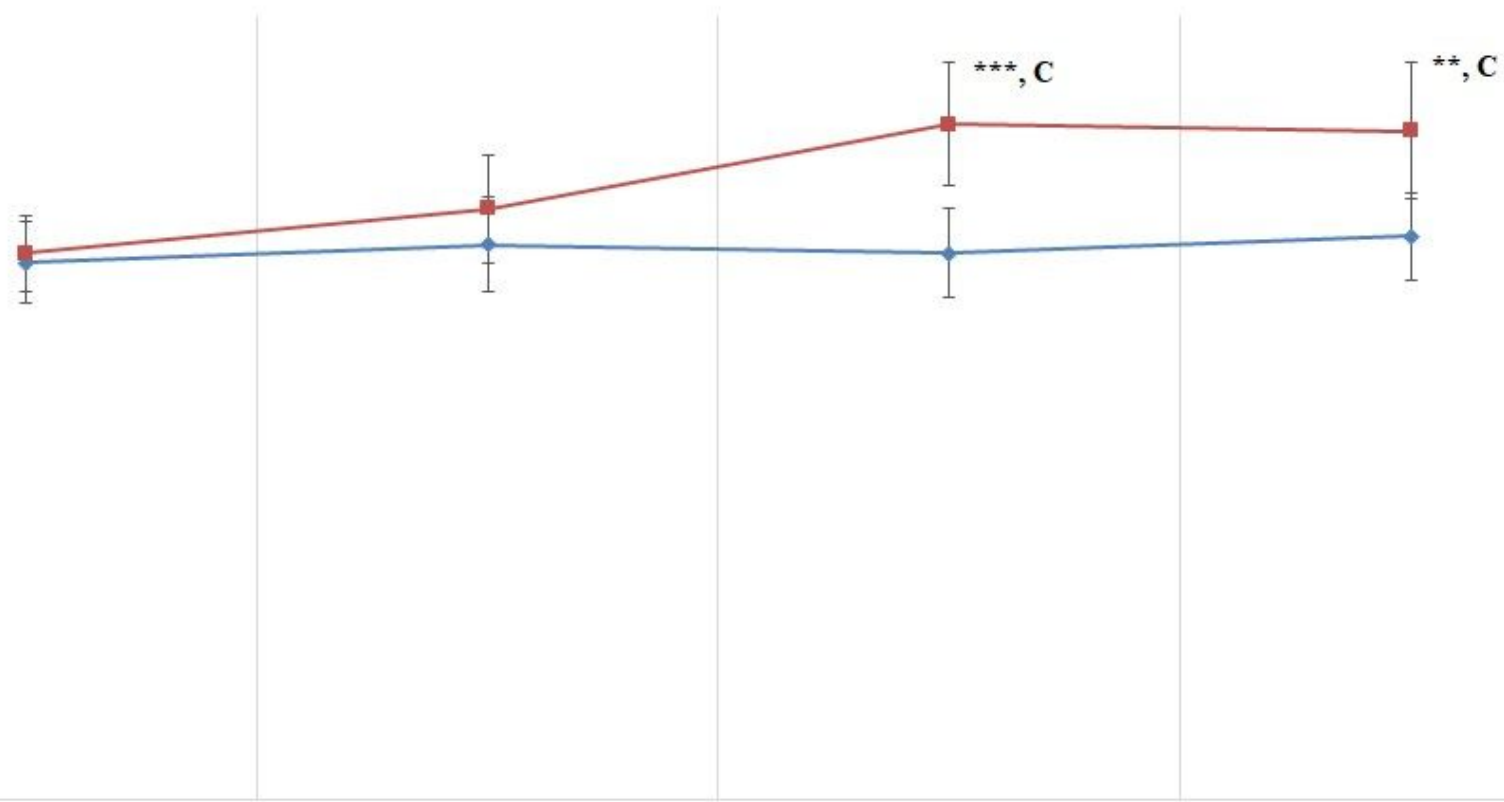

\section{Figure 3}

The chemotactic index was calculated by dividing the number of cells that migrated towards fMLP by the number of cells that migrated in the absence of fMLP. Key: I - control group; II - experimental group; SD standard deviation; Numerical results were presented as the arithmetic mean \pm SD. The significance level was set at 0.05 . Asterisks refer to statistically significant differences between control and experimental group within the same sampling day at $* \star p<0.01 ; * \star \star p<0.001 ; C$ refer to statistically significant differences between day "0" and the consecutive sampling days within experimental group at $\mathrm{C}-\mathrm{p}<$ 0.001 . 


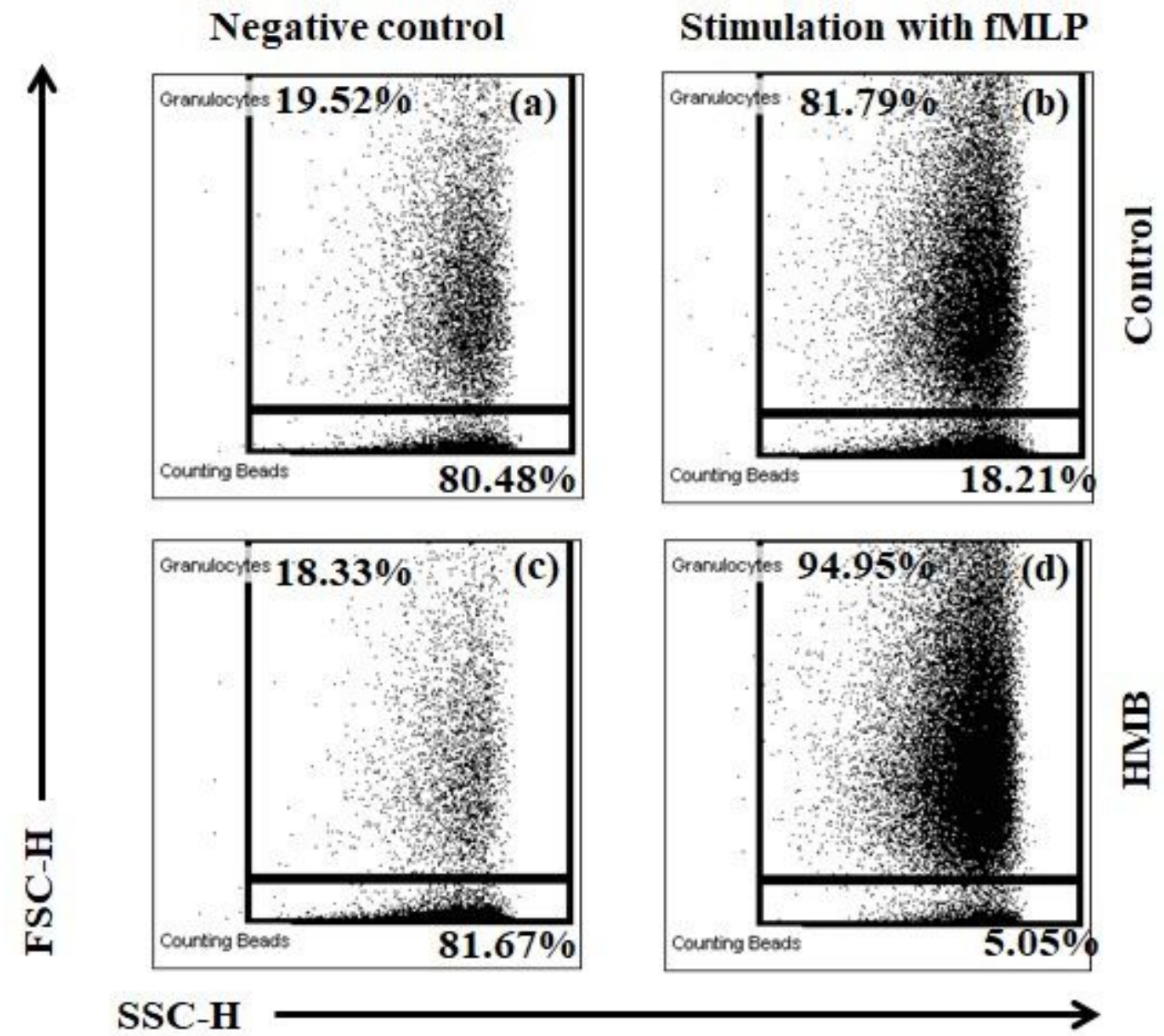

Figure 4

Representative dot plot cytograms showing the percentage of migrating granulocytes and counting beads on day 30 of the experiment. (a) - control without stimulation; (b) - control stimulated with fMLP; (c) - HMB without stimulation; (d) - HMB stimulated with fMLP. The number of granulocytes relative to the number of whole cells was determined in each sample as soon as 2000 counting beads were acquired. Stimulation with $\mathrm{fMLP}$ increased the number of migrated granulocytes (b), (d) relative to the controls without fMLP (a), (c). 


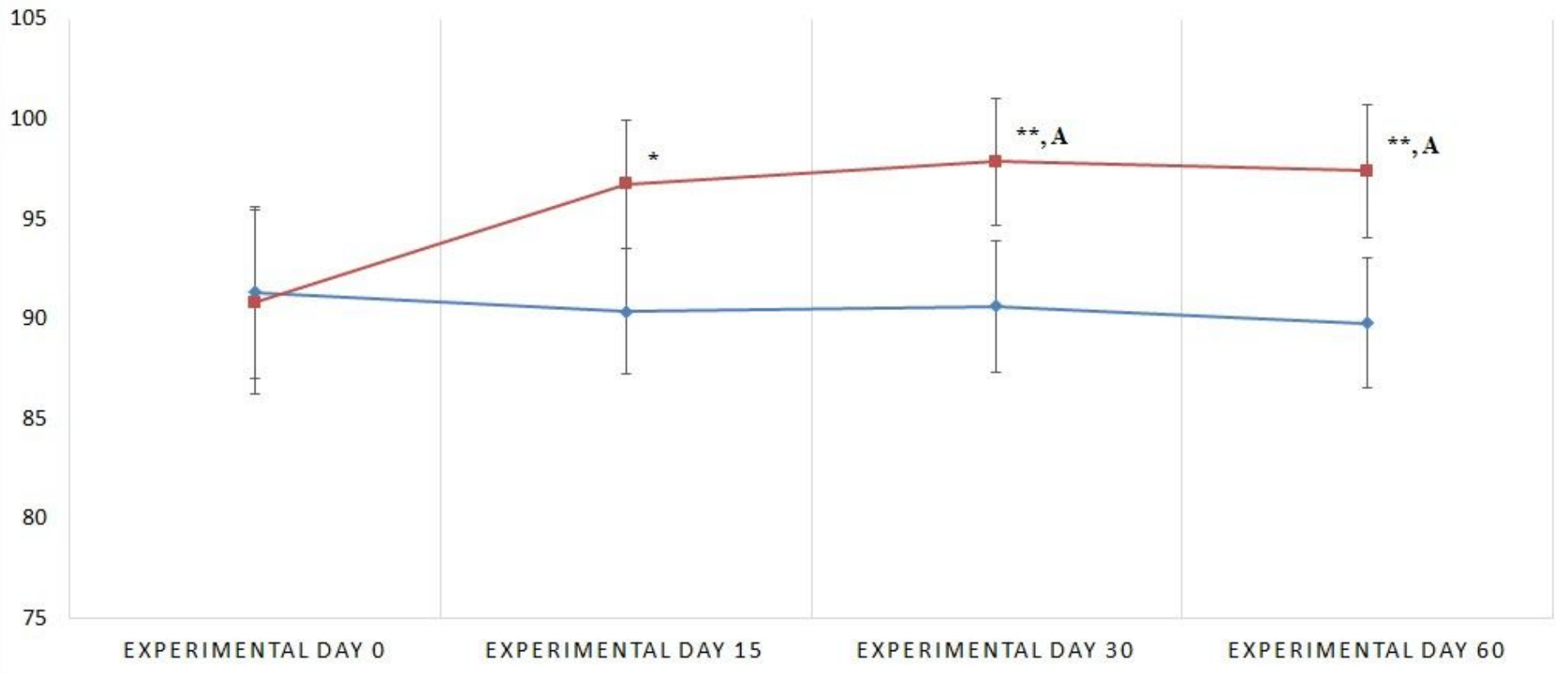

\section{Figure 5}

Percentage of phagocytising granulocytes in calf groups, as determined in the Phagotest@ kit. Key: I control group; II - experimental group; SD - standard deviation. Numerical results were presented as the arithmetic mean $\pm \mathrm{SD}$. The significance level was set at 0.05 . Asterisks refer to statistically significant differences between control and experimental group within the same sampling day at $*<<0.05$; $* \star p<$ 0.01 ; A refer to statistically significant differences between day " 0 " and the consecutive sampling days within experimental group at $\mathrm{A}-\mathrm{p}<0.05$. 

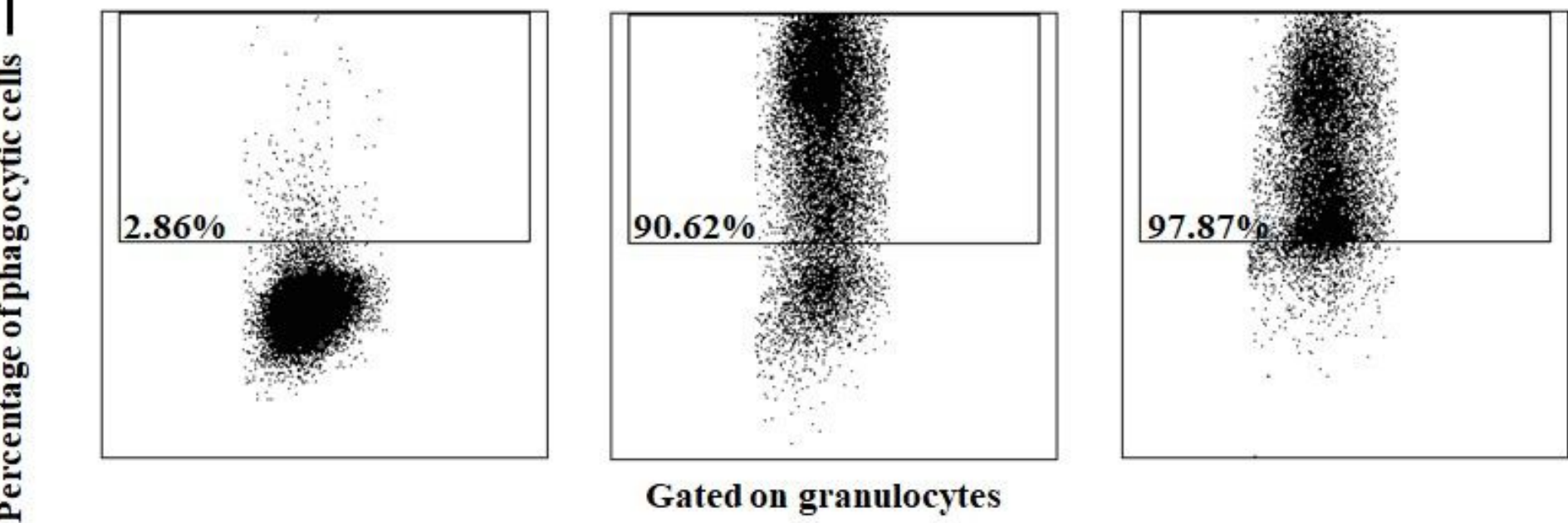

Gated on granulocytes

FSC

Figure 6

Dot plot cytogram showing the percentage of phagocytising granulocytes in control and experimental calves on experimental day 30 . Whole heparinised blood from control and experimental animals was incubated for 10 minutes with FITC-labelled E. coli in an ice bath at a temperature of $0^{\circ} \mathrm{C}$ (negative control) or in a water bath at a temperature of $37^{\circ} \mathrm{C}$ (control and $\mathrm{HMB}$ ). The percentages of granulocytes with ingested E. coli (FITC) bacteria were gated. 
$\multimap$ Mean fluorescence intensity (MFI) of granulocytes ( $\pm \mathrm{SD}$ ) - control group (I)

$\rightarrow-$ Mean fluorescence intensity (MFI) of granulocytes ( \pm SD) - experimental group - HMB (II)

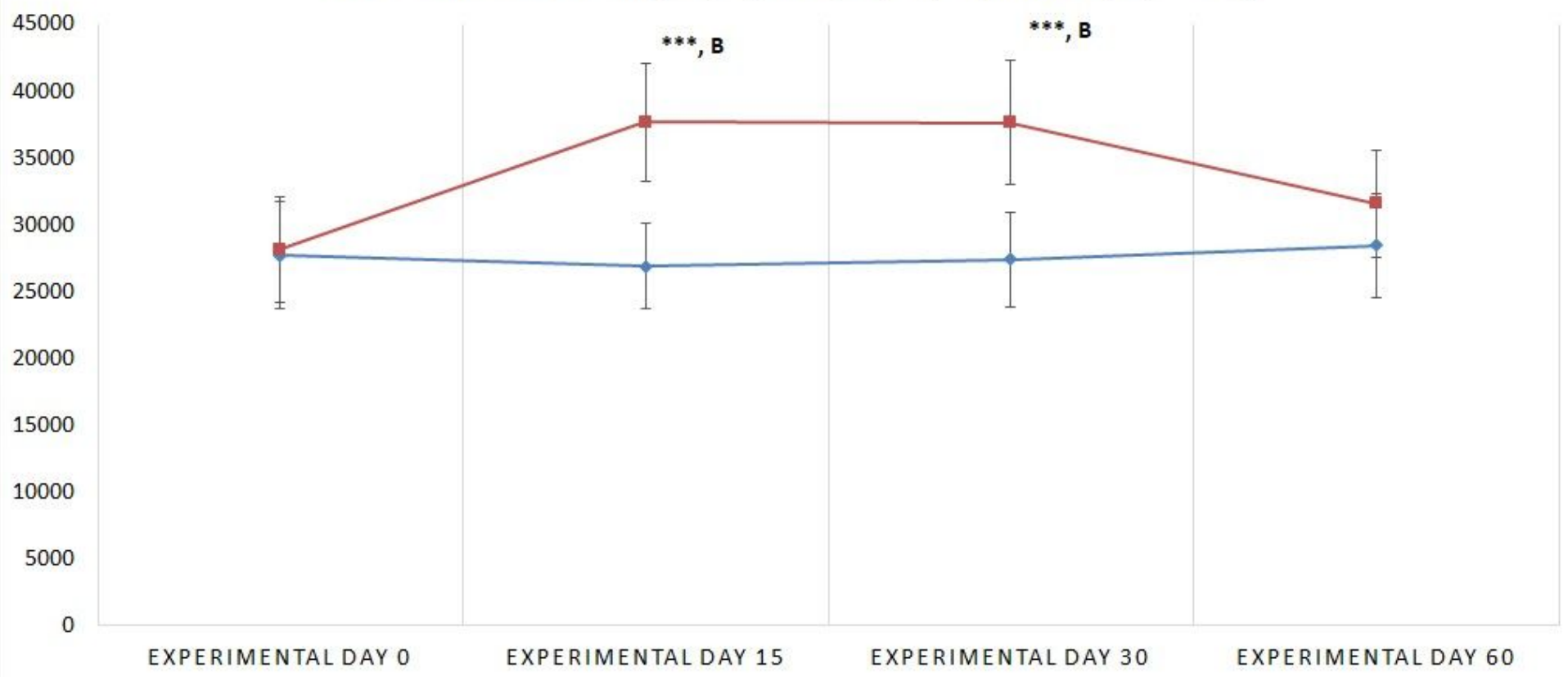

\section{Figure 7}

Mean fluorescence intensity (MFI) of granulocytes in calf groups, as determined in the Phagotest ${ }^{\circledR}$ kit. Key: I - control group; II - experimental group; SD - standard deviation; Numerical results were presented as the arithmetic mean \pm SD. The significance level was set at 0.05 . Asterisks refer to statistically significant differences between control and experimental group within the same sampling day at *** $p<$ 0.001; B refer to statistically significant differences between day " 0 " and the consecutive sampling days within experimental group at B $-p<0.01$. 
$\rightarrow-$ percentage of phagocytic monocytes $( \pm S D$ ) - control group (I) - - - percentage of phagocytic monocytes $( \pm S D)$ - experimental group - HMB (II)

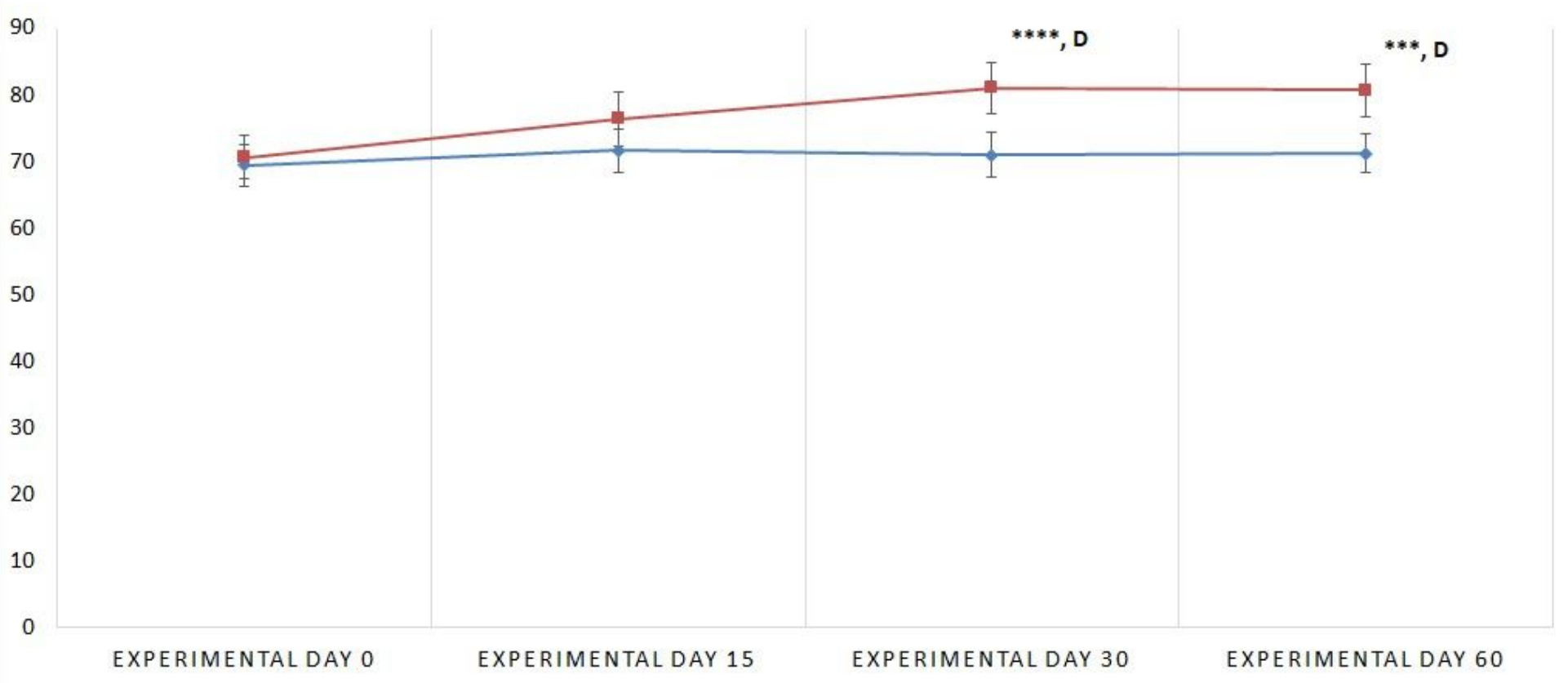

\section{Figure 8}

Percentage of phagocytising monocytes in calf groups, as determined in the Phagotest ${ }^{\circledR}$ kit. Key: I control group; II - experimental group; SD - standard deviation. Numerical results were presented as the arithmetic mean $\pm \mathrm{SD}$. The significance level was set at 0.05 . Asterisks refer to statistically significant differences between control and experimental group within the same sampling day at $\star \star \star p<0.001$; $* \star \star \star p$ $<0.0001$; D refer to statistically significant differences between day "0" and the consecutive sampling days within experimental group at $D-p<0.0001$. 
Negative control

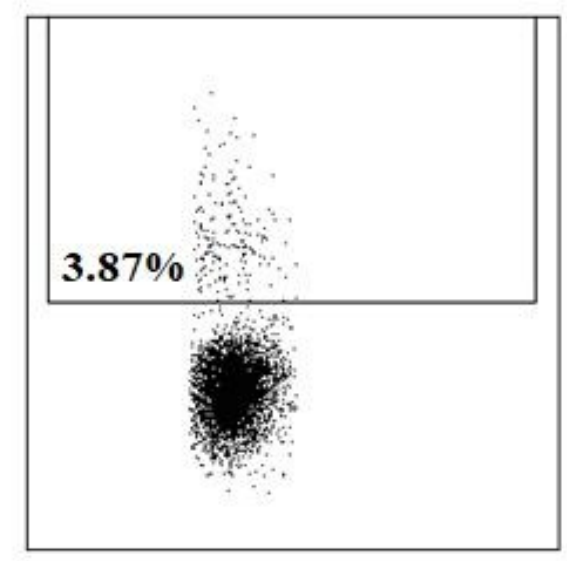

Control

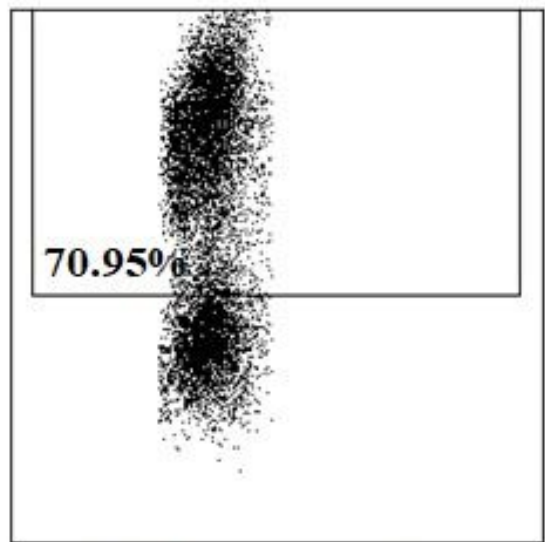

Gated on monocytes
HMB

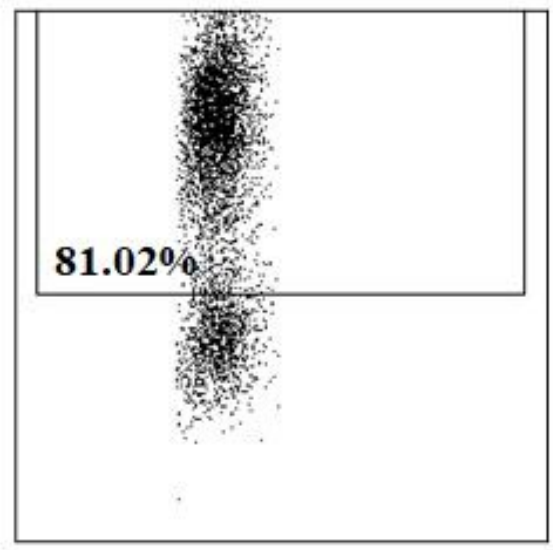

FSC

Figure 9

Dot plot cytogram showing the percentage of phagocytising monocytes in control and experimental calves on experimental day 30 . Whole heparinised blood from control and experimental animals was incubated for 10 minutes with FITC-labelled E. coli in an ice bath at the temperature of $0^{\circ} \mathrm{C}$ (negative control) or in a water bath at the temperature of $37^{\circ} \mathrm{C}$ (control and $\mathrm{HMB}$ ). The percentages of monocytes with ingested E. coli (FITC) bacteria were gated. 
$\multimap-$ Mean fluorescence intensity (MFI) of monocytes ( \pm SD) - control group (I)

$\rightarrow-$ Mean fluorescence intensity (MFI) of monocytes ( \pm SD) - experimental group - HMB (II)

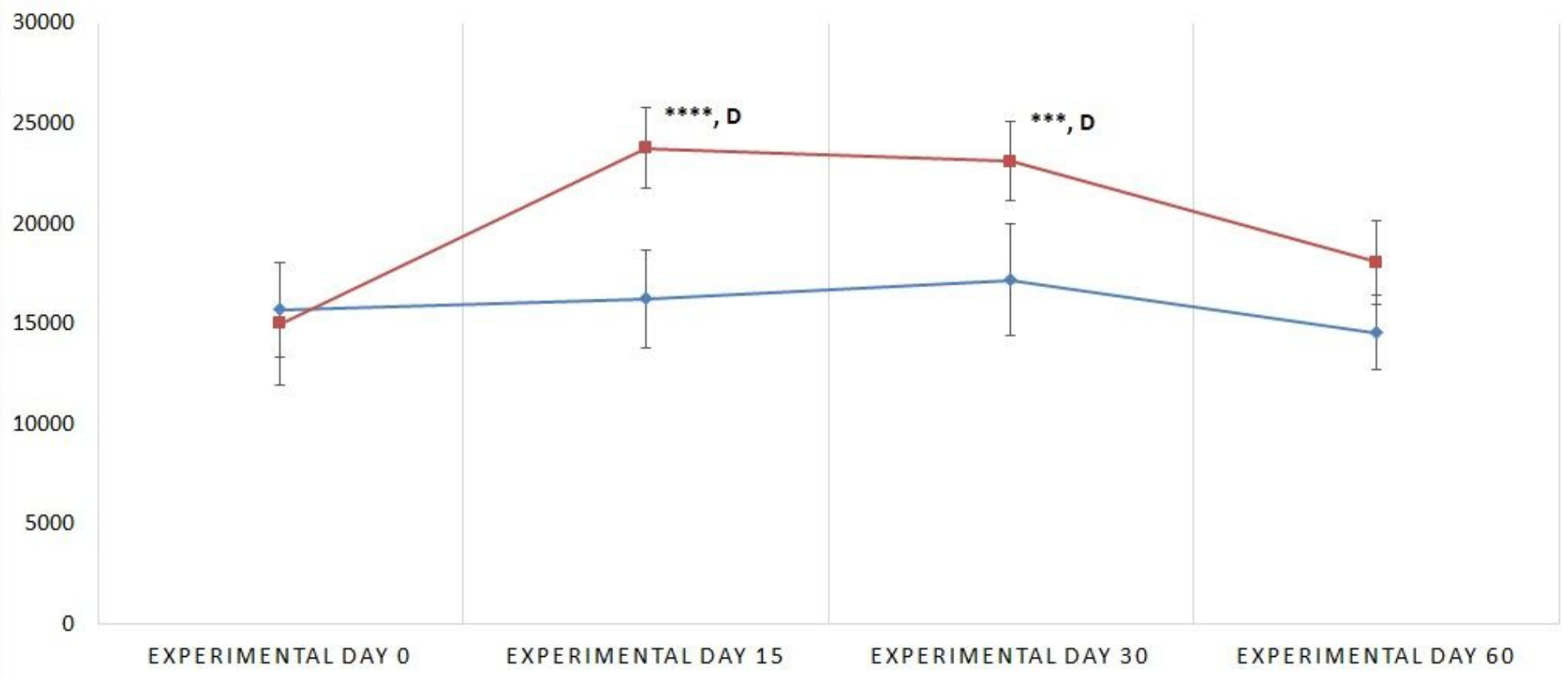

\section{Figure 10}

Mean fluorescence intensity (MFI) of monocytes in calf groups, as determined in the Phagotest ${ }^{\circledR}$ kit. Key: I - control group; II - experimental group; SD - standard deviation. Numerical results were presented as the arithmetic mean $\pm S D$. The significance level was set at 0.05 . Asterisks refer to statistically significant differences between control and experimental group within the same sampling day at ${ }^{\star \star \star} p<0.001 ; * \star \star \star p$ $<0.0001$; D refer to statistically significant differences between day "0" and the consecutive sampling days within experimental group at $D-p<0.0001$. 


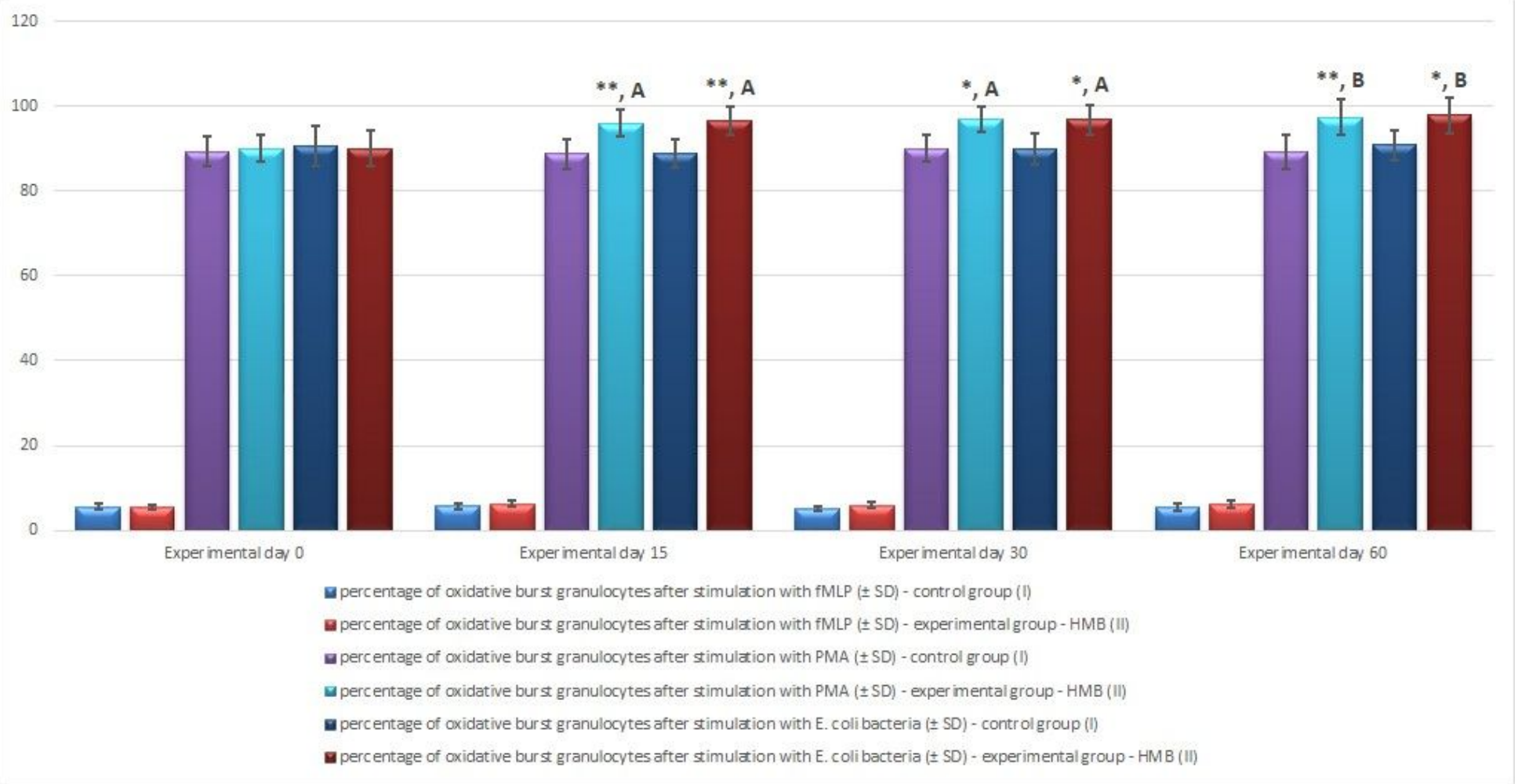

\section{Figure 11}

Percentage of granulocytes stimulated to undergo respiratory burst in calf groups after stimulation with fMLP, PMA and E. coli, as determined in the Bursttest ${ }^{\circledR}$ kit. Key: I - control group; II - experimental group; $S D$ - standard deviation. Numerical results were presented as the arithmetic mean $\pm S D$. The significance level was set at 0.05 . Asterisks refer to statistically significant differences between control and experimental group within the same sampling day at * $p<0.05$; $* *<0.01 ; A, B$ refer to statistically significant differences between day " 0 " and the consecutive sampling days within experimental group at $A-p<0.05 ; B-p<0.01$. 


\section{Negative control}
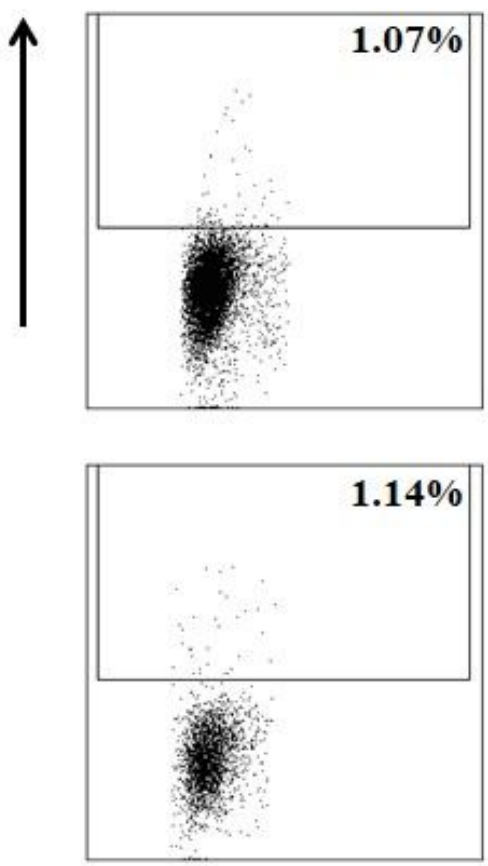

Stimulation with

E.coli bacteria
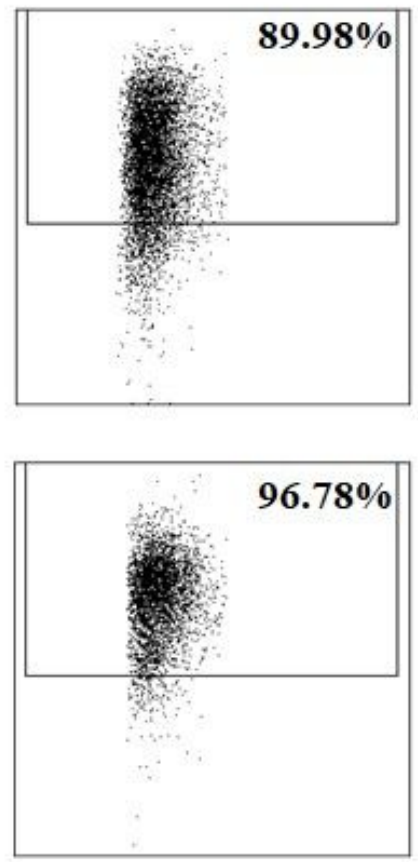

Stimulation with PMA
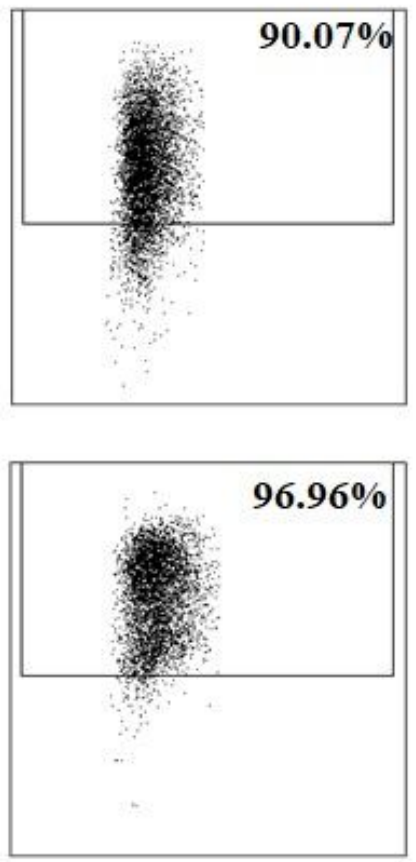

Stimulation with fMLP

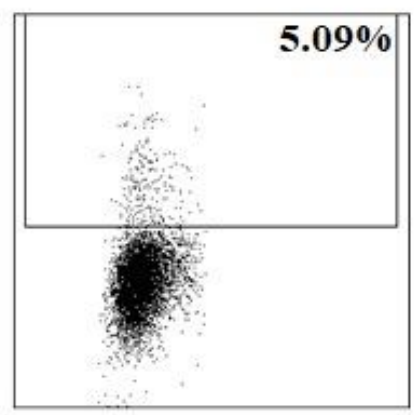

ํㅡㄹ

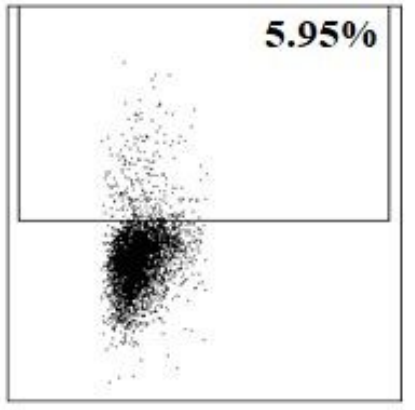

\section{Gated on granulocytes}

FSC

\section{Figure 12}

Dot plot cytogram showing the percentage of granulocytes stimulated to undergo respiratory burst in control and experimental calves on experimental day 30 . Whole heparinised blood from control and experimental animals (control and HMB) was divided into four test tubes. The samples were combined with the washing solution (negative control), E. coli bacteria (opsonising activator), PMA (strong activator) or fMLP (weak activator) and incubated with dihydrorhodamine 123 in a water bath at a temperature of $37^{\circ} \mathrm{C}$. After incubation, cells were lysed and DNA staining solution was added. The percentages of granulocytes stimulated to undergo respiratory burst (conversion of dihydrorhodamine 123 to rhodamine 123) were gated. 


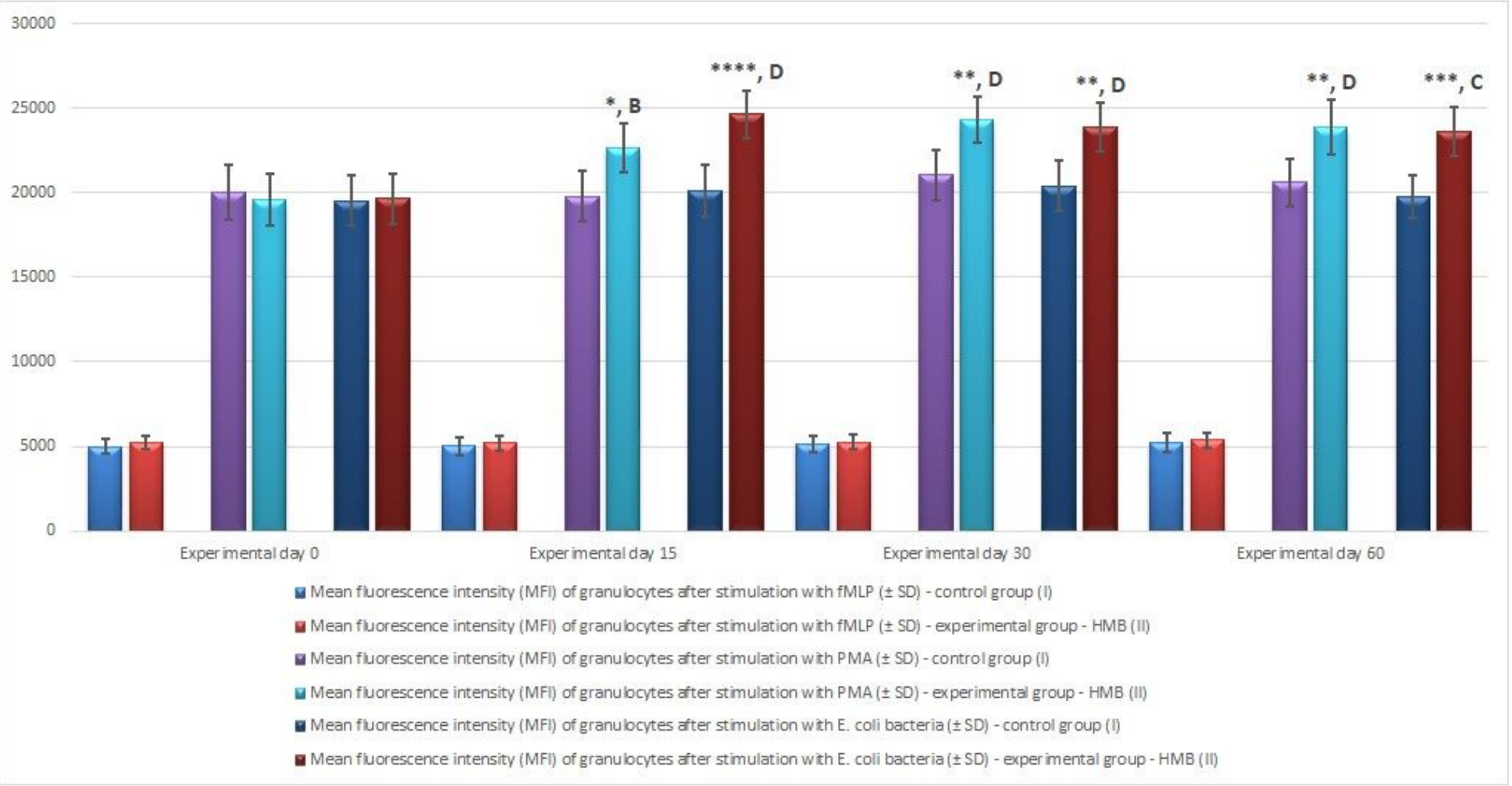

Figure 13

Mean fluorescence intensity (MFI) of granulocytes in calf groups after stimulation with FMLP, PMA and E. coli, as determined in the Bursttest ${ }^{\circledR}$ kit. Key: I - control group; II - experimental group; SD - standard deviation. Numerical results were presented as the arithmetic mean \pm SD. The significance level was set at 0.05. Asterisks refer to statistically significant differences between control and experimental group

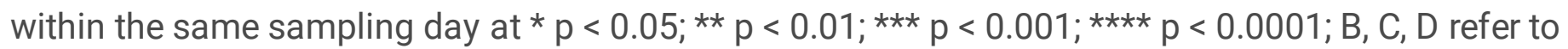
statistically significant differences between day " 0 " and the consecutive sampling days within experimental group at $B-p<0.01 ; C-p<0.001 ; D-p<0.0001$. 


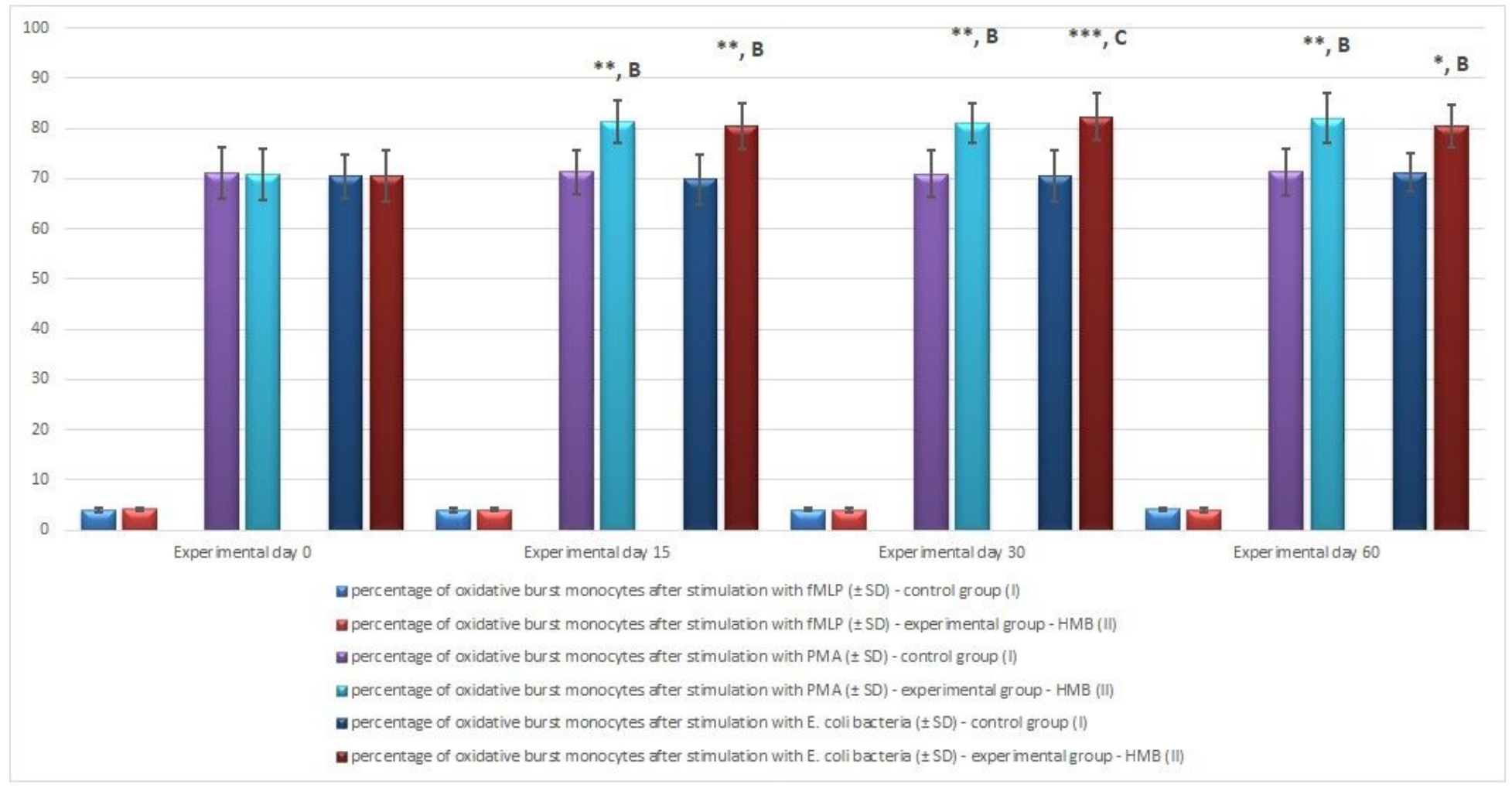

Figure 14

The percentage of monocytes stimulated to undergo respiratory burst in calf groups after stimulation with $f M L P, P M A$ and E. coli, as determined in the Bursttest ${ }^{\circledR}$ kit. Key: I - control group; II - experimental group; SD - standard deviation. Numerical results were presented as the arithmetic mean \pm SD. The significance level was set at 0.05 . Asterisks refer to statistically significant differences between control and experimental group within the same sampling day at ${ }^{*} p<0.05 ; * \star p<0.01 ; * \star \star p<0.001 ; B, C$ refer to statistically significant differences between day " 0 " and the consecutive sampling days within experimental group at $B-p<0.01 ; C-p<0.001$. 


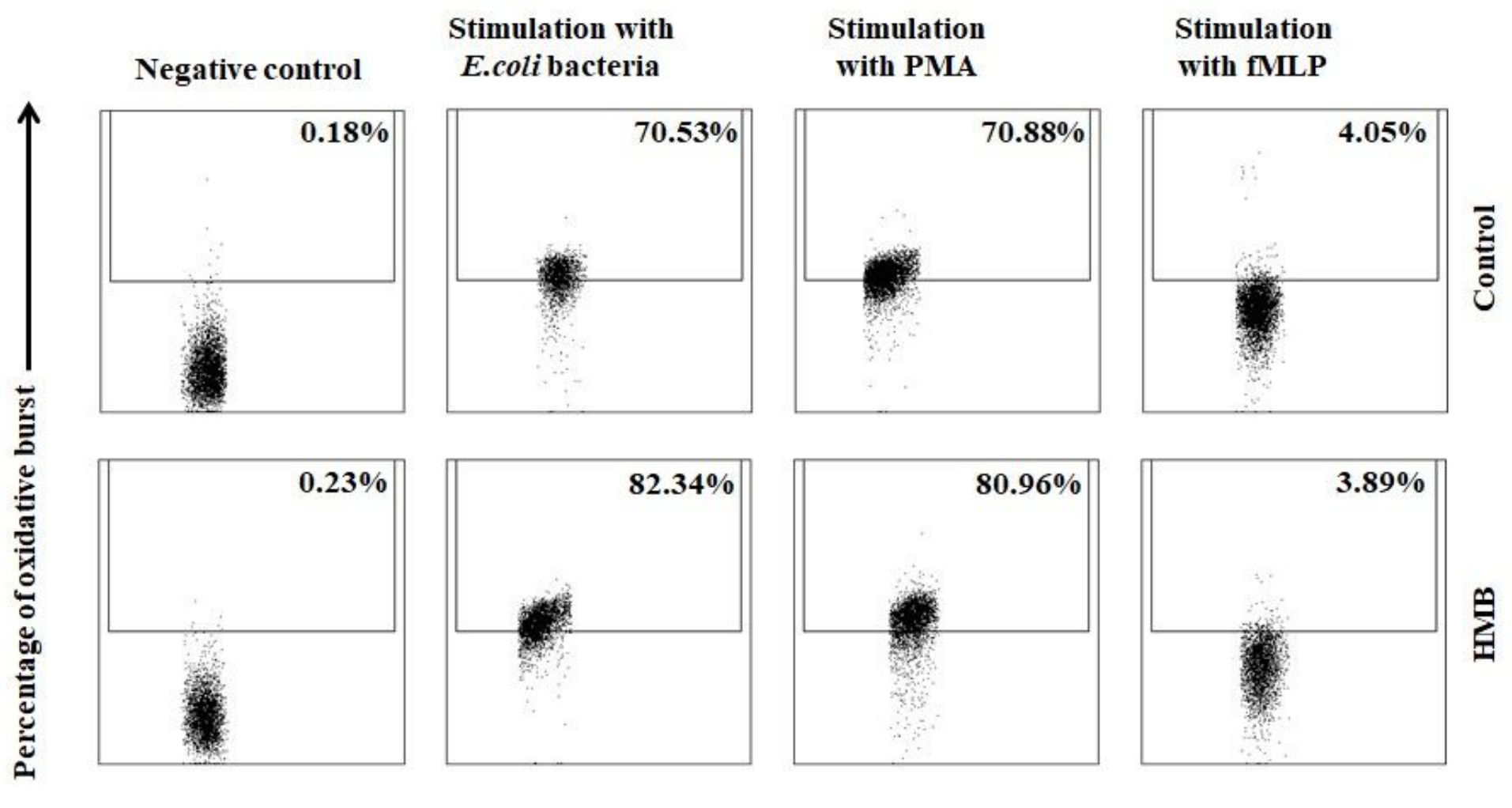

Gated on monocytes

FSC

Figure 15

Dot plot cytogram showing the percentage of monocytes stimulated to undergo respiratory burst in control and experimental animals on experimental day 30 . The percentages of monocytes stimulated to undergo respiratory burst were gated. 


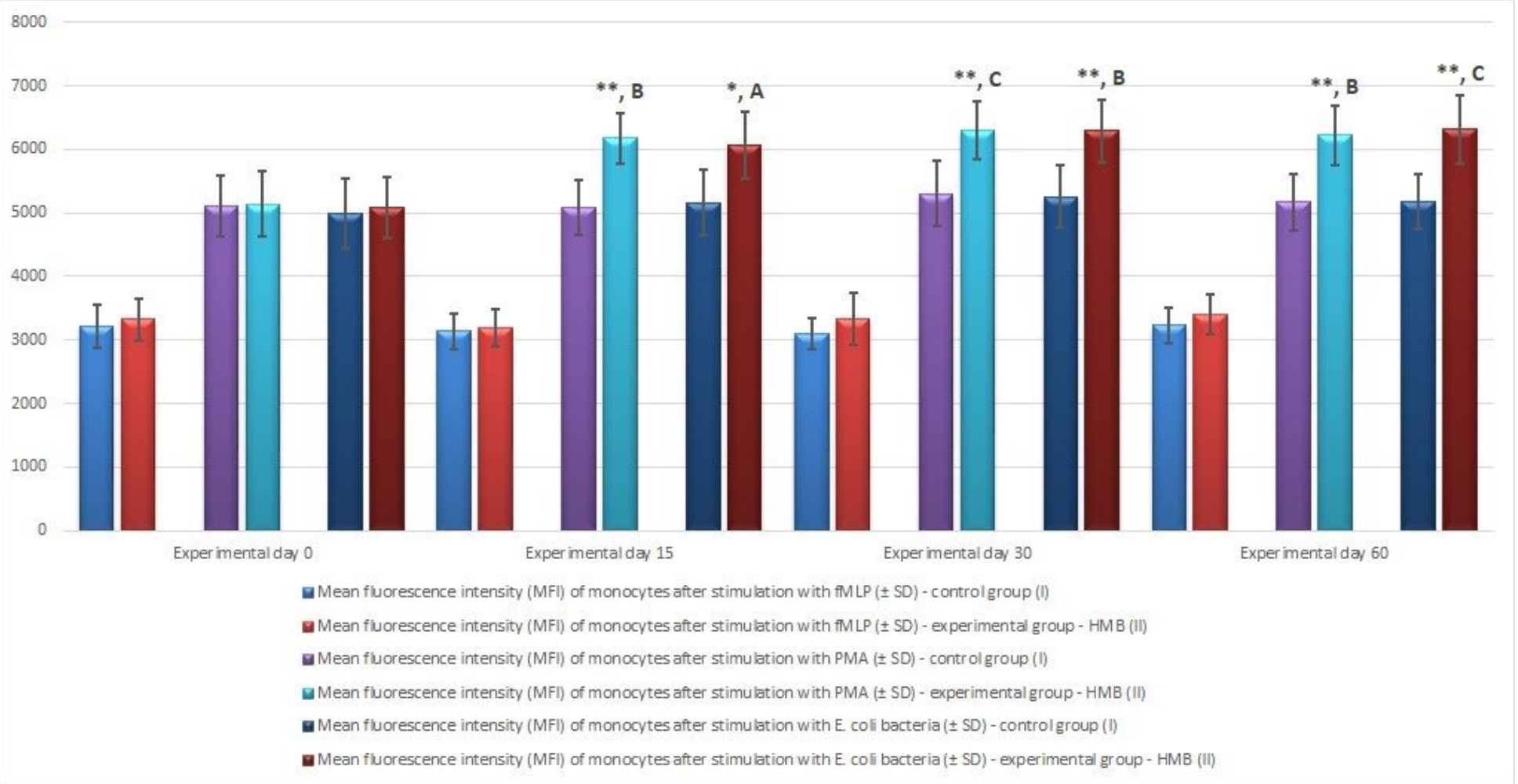

Figure 16

Dot plot cytogram showing the percentage of monocytes stimulated to undergo respiratory burst in control and experimental animals on experimental day 30 . The percentages of monocytes stimulated to undergo respiratory burst were gated.

\section{Supplementary Files}

This is a list of supplementary files associated with this preprint. Click to download.

- NC3RsARRIVEGuidelinesChecklistfillable.pdf 